$9 / 2 / 20-95 y 562$

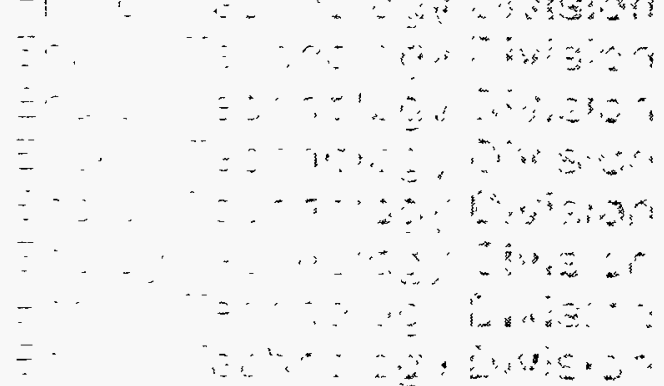

Energy Technology Division Energy Technology Division Energy Technology Division Energy Technology Division Energy Technology Division Energy Technology Division

\section{User Interface Program for Secure Electronic Tags}

\author{
by Y. Cai, E. R. Koehl, R. D. Carlson, \\ and A. C. Raptis
}

Argonne National Laboratory, Argonne, Illinois 60439 operated by The University of Chicago

for the United States Department of Energy under Contract W-31-109-Eng-38

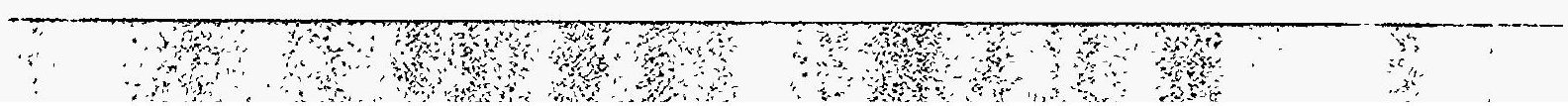


Argonne National Laboratory, with facilities in the states of Illinois and Idaho, is owned by the United States government, and operated by The University of Chicago under the provisions of a contract with the Department of Energy.

\section{DISCLAIMER}

This report was prepared as an account of work sponsored by an agency of the United States Government. Neither the United States Government nor any agency thereof, nor any of their employees, makes any warranty, express or implied, or assumes any legal liability or responsibility for the accuracy, completeness, or usefulness of any information, apparatus, product, or process disclosed, or represents that its use would not infringe privately owned rights. Reference herein to any specific commercial product, process, or service by trade name, trademark, manufacturer, or otherwise, does not necessarily constitute or imply its endorsement, recommendation, or favoring by the United States Government or any agency thereof. The views and opinions of authors expressed herein do not necessarily state or reflect those of the United States Government or any agency thereof.

Reproduced from the best available copy.

Available to DOE and DOE contractors from the Office of Scientific and Technical Information

P.O. Box 62

Oak Ridge, TN 37831

Prices available from (615) 576-8401

Available to the public from the National Technical Information Service

U.S. Department of Commerce 5285 Port Royal Road Springfield, VA 22161 


\section{DISCLAIMER}

Portions of this document may be illegible in electronic image products. Images are produced from the best available original document. 
ARGONNE NATIONAL LABORATORY

9700 South Cass Avenue, Argonne, Illinois 60439

ANL-95/16

Distribution

Category:

Nuclear Energy

(UC-940)

\section{User Interface Program for Secure Electronic Tags}

by

Y. Cai, E. R. Koehl, R. D. Carlson, and A. C. Raptis

Energy Technology Division

May 1995

Work supported by

U.S. DEPARTMENT OF ENERGY

Office of Nonproliferation and National Security (NN-1)

Office of Research and Development (NN-20) 

- $\ldots \ldots-\cdots$ 


\section{Contents}

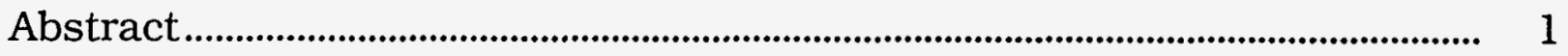

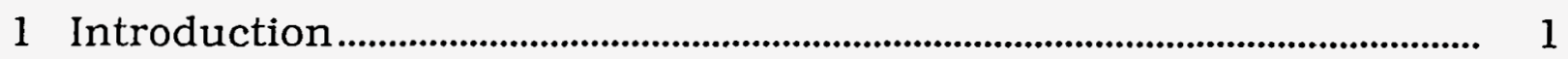

2 Secure Electronic Tags ................................................................................. 5

2.1 LLNL Secure Electronic Tags.............................................................. 5

2.2 Secure Tag Satellite Communications....................................................... 8

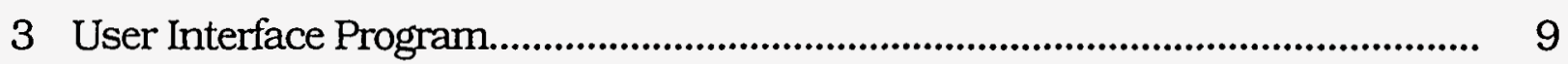

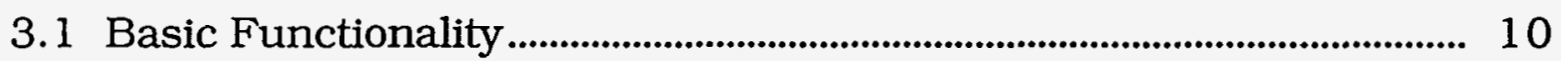

3.2 Program Structure and Specification .................................................... 15

4 Incorporating Tag User Interface into TRANSCOM .................................... 25

4.1 TRANSCOM Tracking System................................................................... 25

4.2 Incorporating Tag User Interface into TRANSCOM ............................ 29

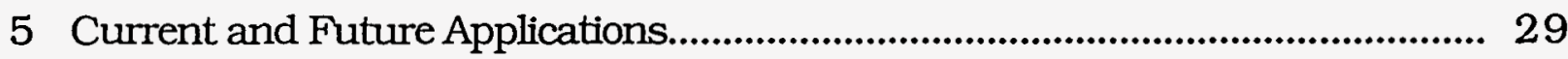

5.1 Warhead Dismantlement and Nonproliferation Treaty...................... 30

5.2 Tracking U.S.-Origin Nuclear Materials in Europe ................................ 30

5.3 Intelligent Transportation Systems............................................................ 30

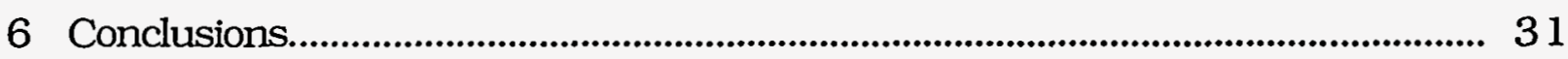

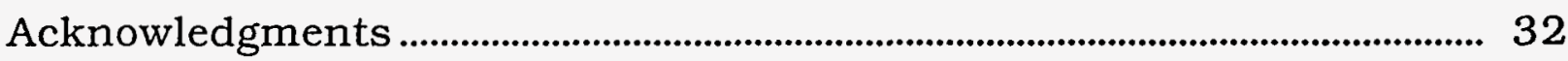

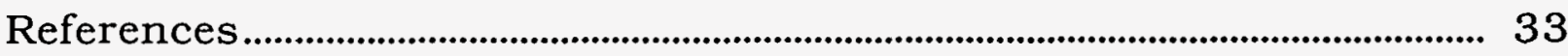

Appendix A: Tag User Interface Program Specifications............................ 34

Appendix B: Tag User Interface Program Flow Chart ....................................... 37

Appendix C: File List of Tag User Interface Program......................................... 41 


\section{Figures;}

1 Secure-electronic-tag technology applied in a tracking system for treaty-limited items............................................................................................. 3

2 Photograph of both sides of SPT prototype tag........................................ 6

$3 \quad$ Photograph of tag, $\mathrm{OBC}$, and RF modem .................................................. 8

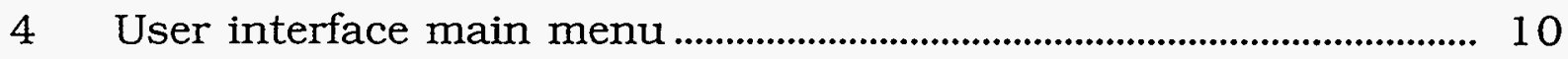

$5 \quad$ User interface main functionality......................................................... 11

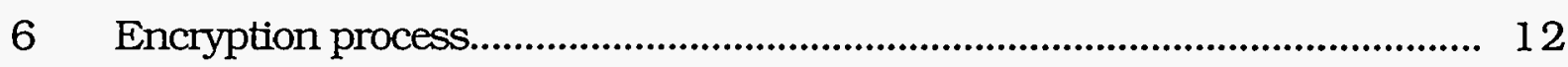

$7 \quad$ Title screen of tag user interface ............................................................. 16

8 Screen for dialing Qualcomm and logging on to NMC.................... 17

9 Display screen of MCT and OBC/TAG communication data............. 18

10 Screen of Execute submenu ...................................................................... 19

11 Screens of Secure-function command selections ............................... 20

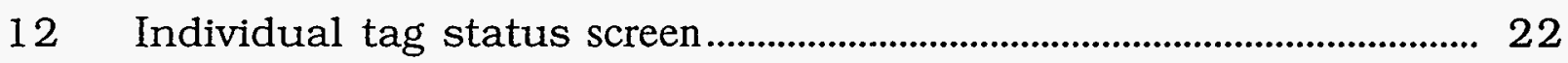

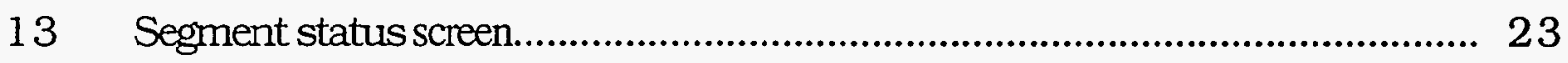

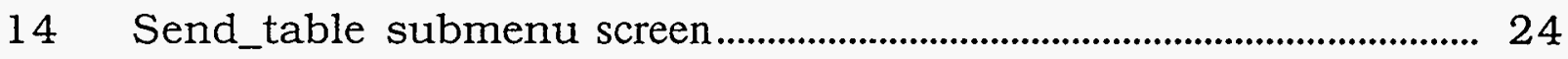

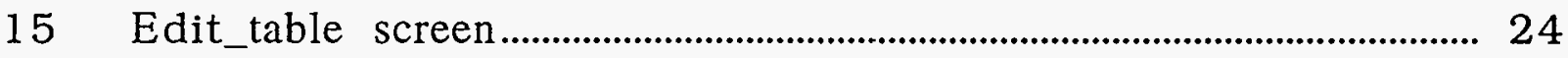

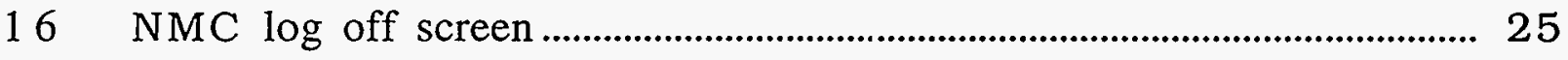

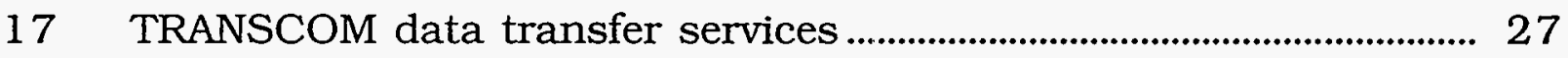

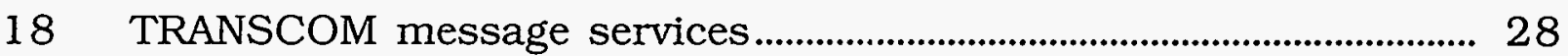

B-1 Flow chart for tag user interface program....................................... 37 
Table

1 List of Secure-command functions ...................................................... 21 


\title{
User Interface Program for Secure Electronic Tags
}

\author{
by
}

\author{
Y. Cai, E. R. Koehl, R. D. Carlson, and A. C. Raptis
}

\section{Abstract}

This report summarizes and documents the efforts of Argonne National Laboratory (ANL) in developing a secure tag communication user interface program comprising a tag monitor and a communication tool. This program can perform the same functions as the software that was developed at the Lawrence Livermore National Laboratory (LLNL), but it is enhanced with a user-friendly screen. It represents the first step in updating the TRANSCOM Tracking System (TRANSCOM) by incorporating a tag communication screen menu into the main menu of the TRANSCOM user program. A working version of TRANSCOM, enhanced with ANL secure-tag graphics, will strongly support the Department of Energy Warhead Dismantlement/Special Nuclear Materials Control initiatives. It will allow commercial satellite tracking of the movements and operational activities of treaty-limited items and transportation vehicles throughout Europe and the former USSR, as well as the continental U.S.

\section{Introduction}

A goal of the Warhead Dismantlement/Special Nuclear Materials Control Program is to develop a system for monitoring the movements and operational activities of treaty-limited items and transportation vehicles. This system will locate transportation vehicles and treaty-limited items and will monitor their movements. It will also transmit location data from stationary or mobile units throughout eastern Europe, the former USSR, and the U.S.

This project proposes that a U.S Department of Energy (DOE) Transcom Tracking System (TRANSCOM) that uses an inexpensive commercial satellite communication system be developed and used to track treaty-limited item movements in the former USSR and elsewhere. 
The commercial aspect of this technology provides an openness that contributes to the acceptance of this approach to movement surveillance by all involved parties. The DOE TRANSCOM does not depend on secure military tracking communications, which could be interpreted by a sovereign state as clandestine tracking of movement of materials through their territory. The DOE TRANSCOM for tracking radioactive material shipments in the U.S. allows states and Indian tribes access to information about shipment quantities and routes through their territories. Similarly, this system would allow all authorized countries and treaty participants access to information about the movement of treaty-limited items. Use by unauthorized parties is prohibited by design.

TRANSCOM uses the Qualcomm Corp. satellite communication and location system. The Qualcomm Corp. controls 24,000 tracking/location units in the U.S. and is adding $\approx 1000$ units per month. The corporation is an established commercial service for satellite communication and tracking/location systems in Europe and has sold more than 1000 units in that market through the satellite service provider EUTELSAT. This service is also available in the former USSR through the service provider COBELLGA, which operates 109 Qualcomm units.

Supporting systems are utilized to complete the surveillance technology. Local area $\mathrm{RF}$ modems allow tracking of each shipment of multiple treaty-limited items and of those items that are secured at each warehouse. The RF modems serve as the interface between secure electronic tags, developed by Lawrence Livermore National Laboratory (LLNL), and a satellite communication/tracking system. This system will have the capability of polling several treaty-limited items with this RF modem technology. An electronic tag will be securely attached to each component to uniquely identify that component. When a tag is polled by a base unit of the Qualcomm system, it will return a coded signal that confirms that the tag is still attached and within the transmitting range of the base unit. In the U.S., the Gualcomm system relays this coded information to the hub in San Diego. The hub for the Eutelsat satellite system, currently near Paris, France, is used for shipments in Europe and the former USSR. Tracking information is transmitted to DOE TRANSCOM headquarters at the Forrestal Building or other appropriate headquarters, as illustrated in Fig. 1. 


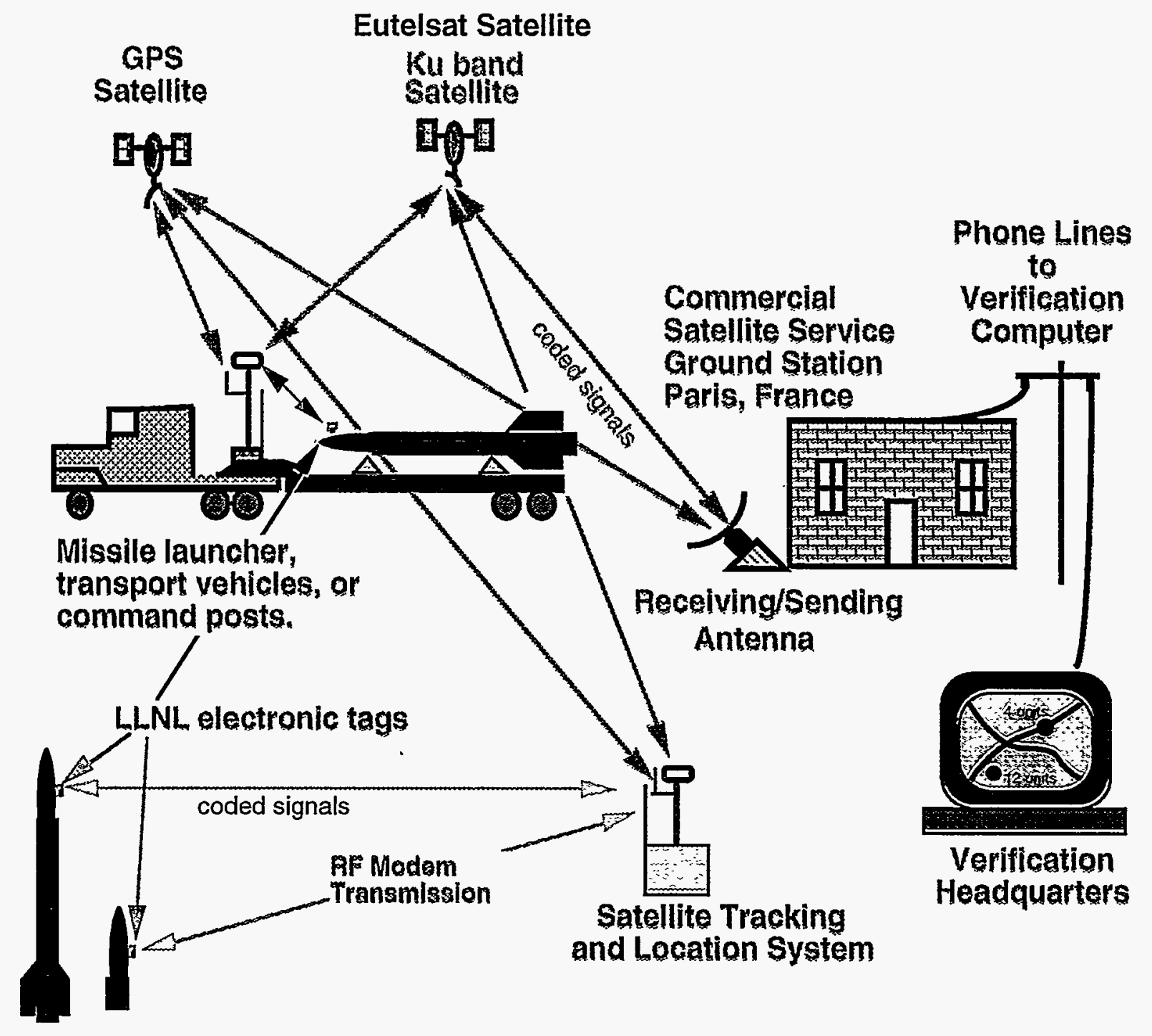

Fig. 1. Secure-electronic-tag technology applied in a tracking system for treaty-limited items

Hardware that will be useful in the verification of treaties in eastern European and western Asian portions of the former USSR have been developed through the Arms Control Program. When linked with satellitebased communication networks, this hardware will allow verification of the location and status of treaty-limited items. The LLNL-developed hardware, uses secure, spoof-proof electronic tags that may be affixed to virtually any object or group of objects. These tags enable remote monitoring agencies to determine the status of both the tag(s) and the item(s) being monitored. If tampering should occur, an internal alarm is set and an alert status is sent on the next poll. The use of a local-area RF modem system allows multiple components of treaty-limited items to be accounted for with one satellite 
communication package in a given area or transportation convoy (Gritton et al, 1993). The technology developed by LLNL is being adapted for use in this project, and the cooperative effort is progressing.

Proprietary software was developed at LLNL to communicate with LLNL tags. This software uses the Qualcomm system, but is not integrated well with political tools currently in use in the U.S. Used by itself, without integration into a politically acceptable system, this software presents many significant political problems.

The DOE Transportation Management Division EM-26I uses TRANSCOM at Oak Ridge, Tennessee, to monitor and track radioactive shipments. Operation of this facility is under contract with the MartinMarietta Corporation, which subcontracts day-to-day activities and staffing to the Security Consultants Group (SCG), which operates TRANSCOM and the TRANSCOM Control Center (TCC).

The current production-system version of TRANSCOM is based on the Phase IV Prototype, revision 2.2, March 1989. The prototype was developed by Argonne National Laboratory (ANL) under Contract 81462401 with Systems Research and Applications, Inc. (SRA), and has subsequently been transferred to DOE Oak Ridge Operations. In the interim, the prototype system has been revised and enhanced to become the production system in use today.

The DOE Office of Research and Development (NN-20), On-site Systems Division, would like to incorporate the LLNL tags into TRANSCOM to facilitate foreign treaty agreements under the Warhead Dismantlement/Special Nuclear Materials Control Program (AL500). In the U.S., TRANSCOM has already been accepted politically.

This report summarizes and documents ANL's effort in developing a user interface program that provides a tag monitor and communication tool. This user interface program can perform the same functions as the LLNL software. but is enhanced with a user-friendly screen menu based on Windows for $\mathrm{C}$ and Windows for Data by Vermont Software. It represents the first step in updating TRANSCOM by incorporating a menu for the tag communication screen into the main menu of the TRANSCOM user program. 


\section{Secure Electronic Tags}

Secure electronic tagging systems were originally developed at LLNL for treaty-verification applications in which tagged treaty-limited items (TLI) could be uniquely identified during inspections. In addition to treaty verification, electronic tags integrated with tamper sensors are expected to be extremely useful to intelligence agencies, the military, and law enforcement officials. Electronic tags are very secure and have features that satisfy a wide spectrum of development scenarios. (Gritton et al., 1993).

\subsection{LLNL Secure Electronic Tags}

LLNL's secure electronic tags are functionally similar to commercial electronic tags in use throughout the world for access control of personnel, automated operations in manufacturing plants, automobile identification, and accounting for movable containers on ships and railroads. The LLNL tags augment commercial tag technology with security features that make them virtually impossible to duplicate. These tags can be attached to an object with an aggressive adhesive. To authenticate the identity of a given tag, the user sends a random number to the tag for encryption. Using internal, programmable keys, the tag's data algorithm encrypts the number and transmits the result back to the user. Every random-number input results in a unique response by the tag's encryption keys. By knowing the tag's encryption keys, a correct match between the tag's input and output is verified.

\subsubsection{Hardware}

An LLNL secure tag is based on integrated circuit technology. A typical tag contains a Motorola 68HC705Bl6 microprocessor and memory die, a Sylvac M7000 series tamper sensor, and discrete input/output logic. The circuit is encapsulated with an antitamper coating material and hermetically sealed in a metal container that serves as a protective barrier and electrical interface with the outside world. The resulting package is approximately the size of three stacked pennies. Figure 2 shows both sides of a prototype tag. 


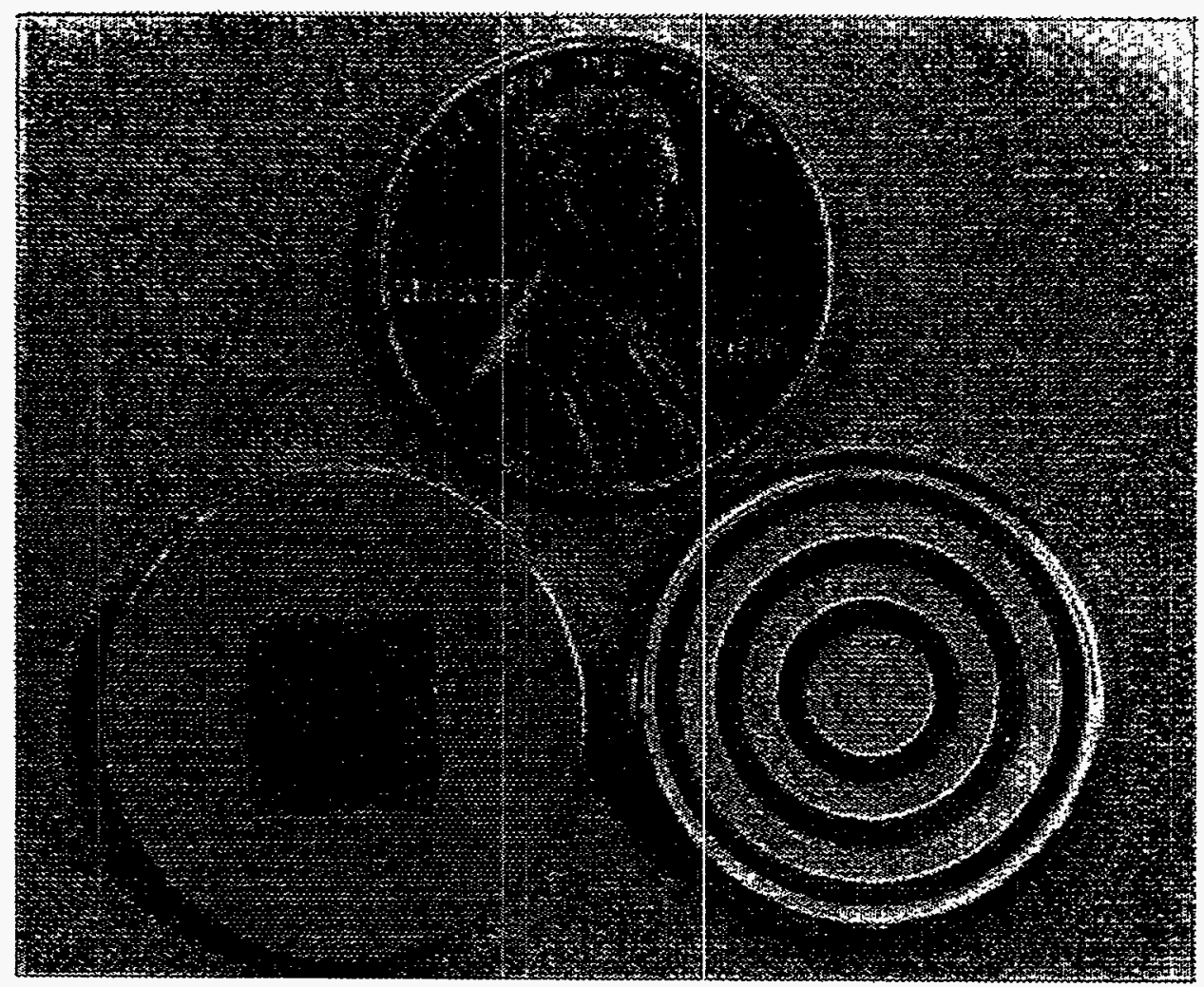

Fig. 2. Photograph of both sides of SPT prototype tag (Gritton et al., 1993)

The heart of the secure electronic tag is a microprocessor chip that contains the encryption keys and communicates with the integrated tamper sensors and the outside world. To prevent an adversary from extracting information directly from this chip, it is coated with a protective composite material developed at LLNL to protect classified electronics.

\subsubsection{Software}

The tag is controlled by a program residing in read-only-memory. The program consists of command and control functions to implement several routines, e.g., status monitor, status report, execution of secure functions, data encryption, tag identification, ranging, tamper sense/alarm, and data input/output.

To communicate with the tag program, researchers at LLNL have developed a custom user program, LLNL_NMC.EXE, which operates in a DOS environment. This program interfaces with the Qualcomm satellite communications and tracking system (SatCom) and contains 24 commands, 
which are in four categories: control, inspection challenge, authentication, and data retrieval. Twenty-two commands are in use and two are reserved for future use.

\subsubsection{Peripheral Hardware}

An on-board computer $(\mathrm{OBC})$ is curently employed between the tag and SatCom as a protocol and handshake translator. The OBC is based on an intel 80386 and contains five tables of tag stimuli sequences. When the user initiates any one of these sequences, it is the $O B C$, not the user's computer, that actually interfaces with the tags. The user can edit, download to, and retrieve the tables from the $O B C$. For example, when an acquire data sequence is executed, the user sends the character string "\$700F00" to a named tag. The OBC intercepts the string and initiates a sequence of commands that is saved in the Acquire Data Table in the OBC's CMOS RAM.

The physical link between the SatCom hardware and the secure tag/OBC is made by a pair of $\mathrm{RF}$ modems. These modems produce $\approx 0.5 \mathrm{~W}$ of power in the 908-928 MHz band and utilize spread-spectrum technology. The predicted range between an operating pair of modems is 0.5 mile.

Both the secure tag/OBC and the SatCom hardware are currently powered by $12 \mathrm{~V}$ storage batteries that are recharged with passive solar photovoltaic arrays. Figure 3 shows the tag, OBC, and RF modem. 


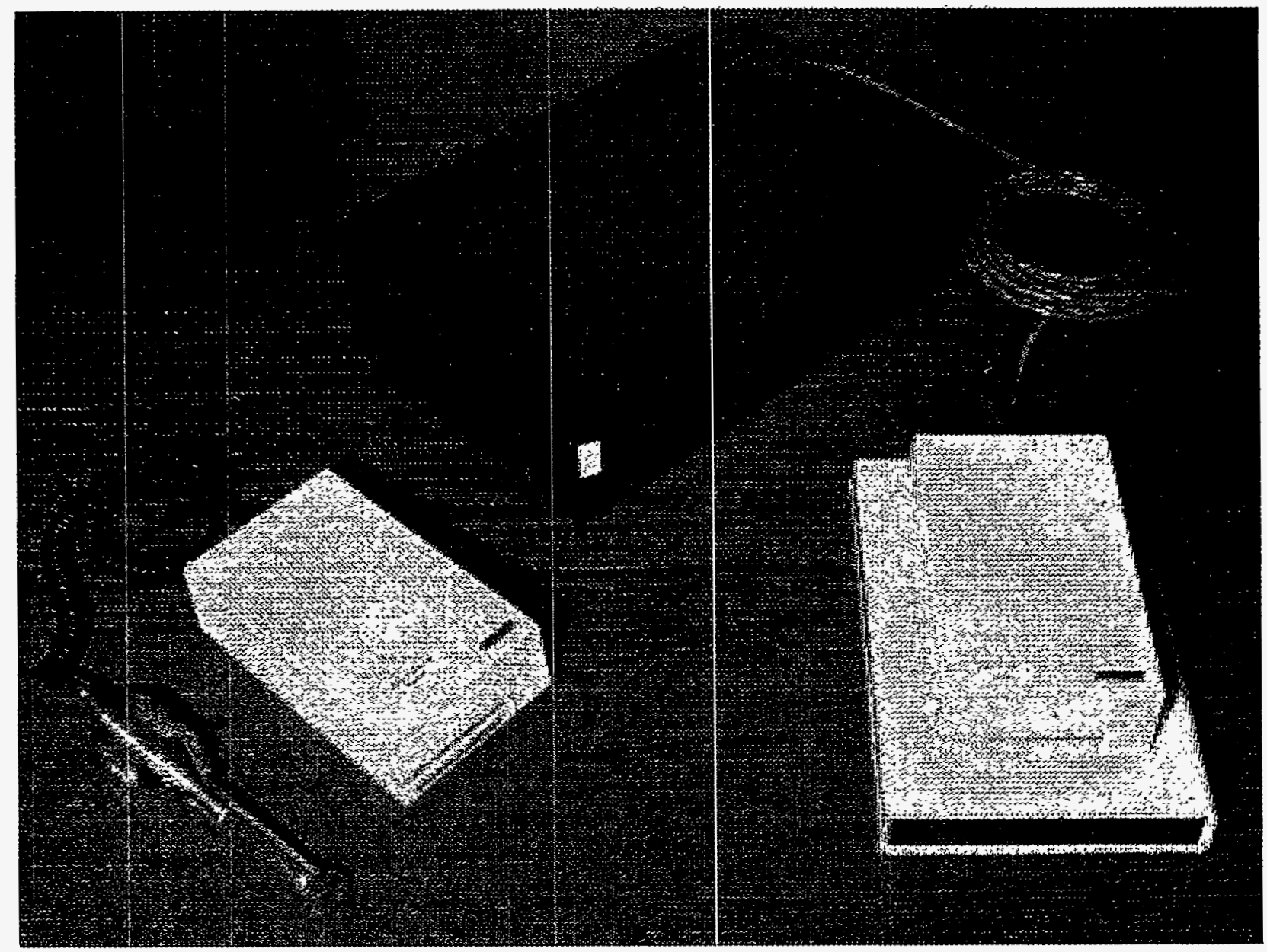

Fig. 3. Photograph of tag, $O B C$, and $R F$ modem

\subsection{Secure Tag Satellite Communications}

The secure-electronic-tag system utilizes the commercially available Qualcomm OmniTRACS satellite communication and location system, as does TRANSCOM. Therefore, the Qualcomm user interface protocol plays an important role in secure-tag satellite communication.

Because TRANSCOM and the tag monitor and tracking system focus on sending and receiving messages, it is informative to briefly discuss the relationship between Qualcomm and any user of their satellite communication system. Qualcomm publishes a booklet entitled Customer Interface Packet Specification. which outlines the communication protocol to which any user of their satellite system rnust conform. 
The user logs on to Qualcomm's Network Management Computer (NMC) with a unique user identification and password, and using communication software, generates and receives information in the form of character string packets. These packets are forwarded to and returned from a mobile communication terminal (MCT), which is the SatCom package assigned to the user.

Each packet is of a specific type and sometimes contains a subtype. Two types of packets handle message traffic, i.e., a message submittal packet (type 105) and a return message packet (type 115). The former contains two subtypes, the latter has six. For message submittal, the user may choose a text or binary data message. Normally, the MCT handles only text messages sent between the user and the transportation vehicle; however, the tags send binary data. The same holds true for return messages, i.e., a return message from a tag will be of a different subtype and subsequently will be packaged differently than a regular test-containing return message. Regardless of whether LLNL's or TRANSCOM's software is used, the user must adhere to the specifications and protocols established by Qualcomm.

\section{User Interface Program}

A tag communication and user interface, which provides users a tag monitor and communication tool, was recently developed at ANL. This user interface program can perform the same functions as the LLNL software, but is enhanced with a user-friendly screen menu based on Windows for $\mathrm{C}$ and Windows for Data.

The purpose of developing this tag interface program was to gain insight into the operation of Windows for C/Data, to update TRANSCOM by incorporating a tag communication screen menu into the main menu of the TRANSCOM User Program, and to update LLNL's tag software with interface functionality.

The screen menu of the tag user interface includes Main Program, Receive \& View Messages, Execute Stimulus, Send Secure Commands, Check Tag Status, and Edit \& Send Tables, as shown in Fig. 4. 


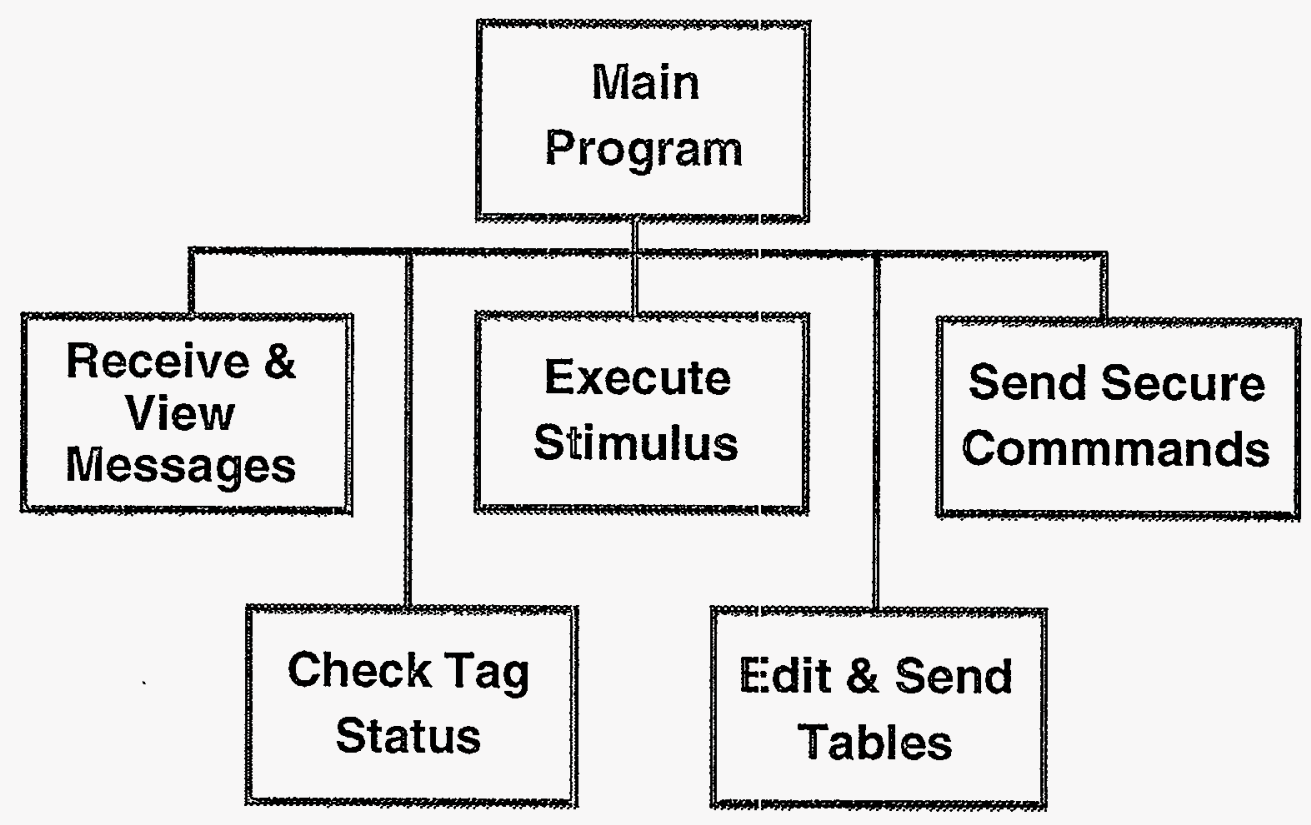

Fig. 4. User interface main menu

\subsection{Basic Functionality}

The tag user interface will include the same functions as the LLNL software, but with functions reorganized under the new screen menu indicated in Fig. 4. The major functionalities within the main menu are listed in Fig. 5; they will be discussed in detail later. 


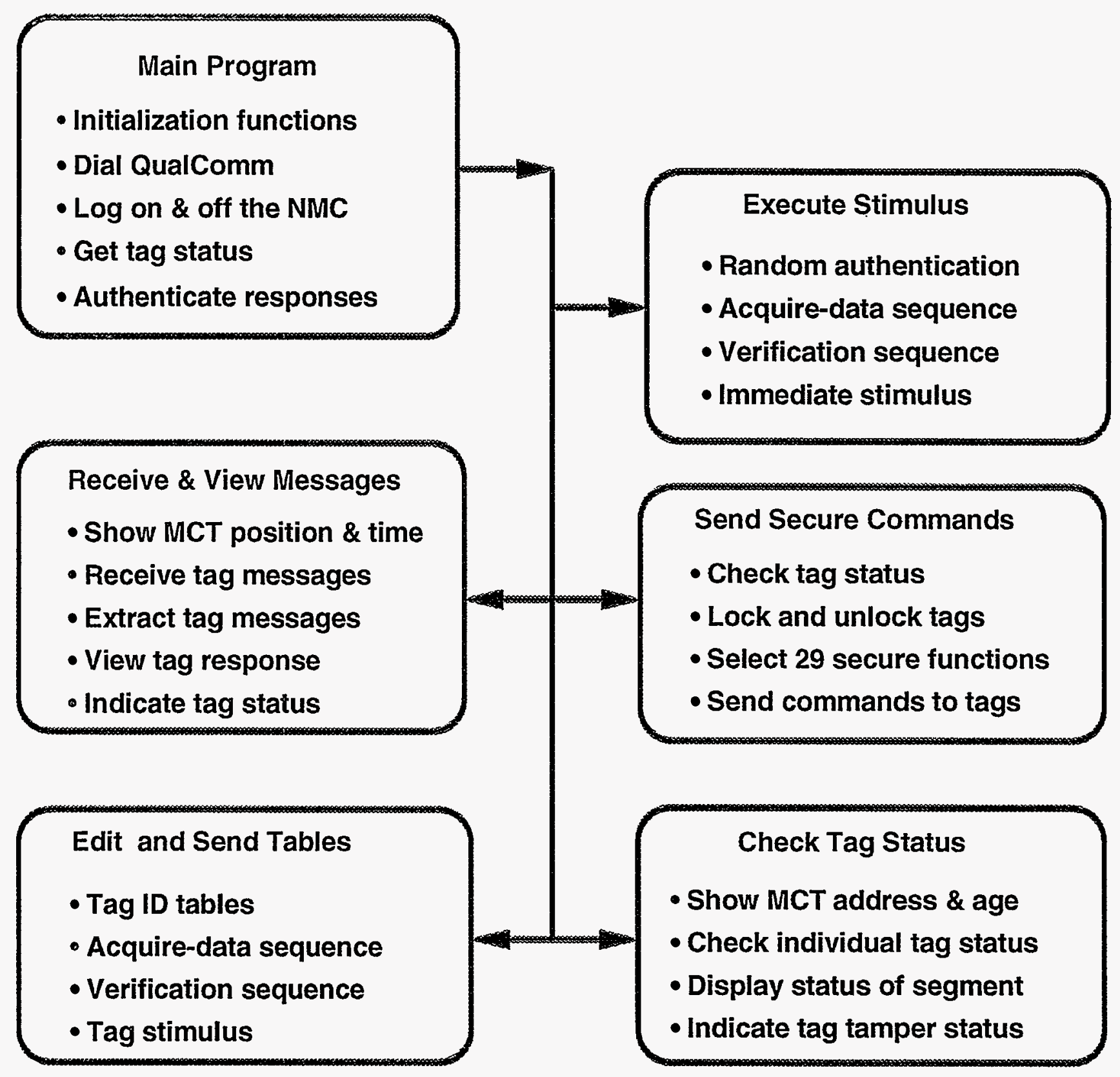

Fig. 5. User interface main functionality

In addition, to completely understand the tag user interface, we briefly describe the basic functionalities that are related to the design features of LLNL's tag.

\subsubsection{Encryption}

The heart of the tag is its encryption processor. Inspection challenges are used to authenticate and verify tag responses to positively identify the 
tang with which the user is communicating and provide some assurance of the quality of the information obtained from the tag.

An authentication command sends a random string of numbers to the tag and once the tag receives the string, it encrypts the string with its internal keys and then returns the result to the user. Because the user program knows the tag's internal encryption keys, it can locally encrypt the challenge sent to the tag and compare the result received from the tag to the local string.

A match between the two strings assumes that the tag has been positively identified or authenticated. Figure 6 illustrates how the tag identity is authenticated.

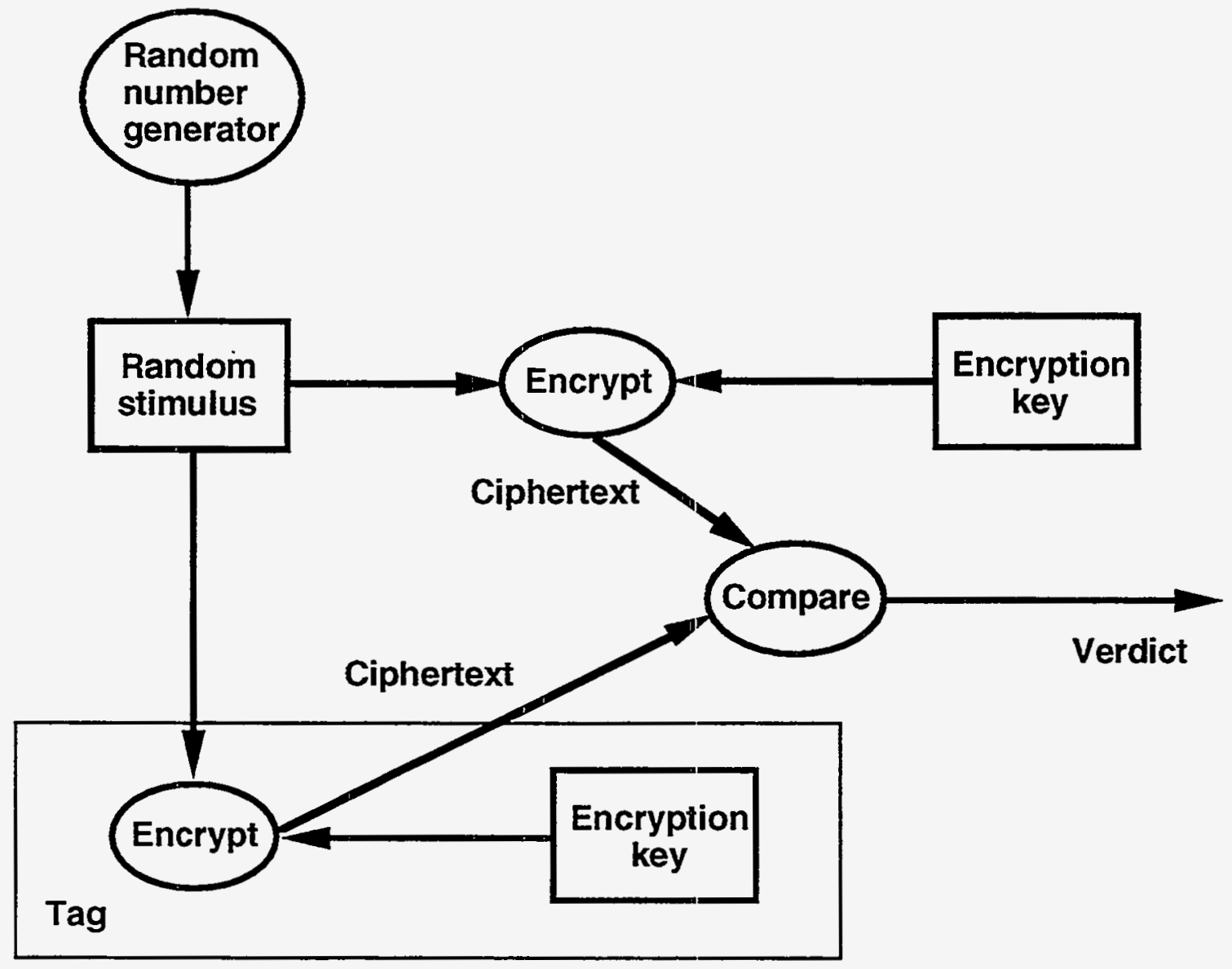

Fig. 6. Encryption process 


\subsubsection{Verification Process}

Because of the digital nature of electronic tags, the signature correlation process is unambiguous. A tag's identity is authenticated by evaluating its encrypted response with an expected response. The proper response is obtained by performing an independent encryption of the same stimulus with another computer that contains the same encryption keys as the tag.

A verification command refers to the quality of the data communication between reader and tag. All communications are error-checked and if no errors occur, the data are referred to as verified. A verification sequence gathers sufficient data from the tag to authenticate its identity and ensure its status.

A fine distinction is made between the terms verification and authentication. Verification refers to data validation required before authentication can be initiated. Authentication is the process of comparing expected tag responses with actual tag responses.

\subsubsection{Ranging}

Ranging is a technique employed to determine proximity of the intended tag to the interrogator. The concept of ranging by measuring the round-trip time delay is a standard technique for radar systems. However, when a remote device, as well as the intervening medium, is under adversarial control, misleading range results can be produced. The selected ranging technique would add an additional time delay to the round-trip propagation that depends on the tag's encryption keys. Thus, the tag always gives a false range signal, with the difference between actual range and reported range depending on an encrypted number.

\subsubsection{Control Options}

The response of a tag to a stimulus varies, depending on its internal control parameters, the specific stimulus, and potential error conditions. Changes to the tag's internal operational status are effected through secure stimuli. To formulate responses, the user program must know the tag's encryption keys. The tag's internal configuration is thus protected at the same security level as its authentication capacity. The tag's response to a stimulus can be affected by its internal configuration. 


\subsubsection{Tag Lock (locked/unlocked)}

If locked, the tag will respond to only two stimuli when power is applied. The first stimulus is a request for identification information, the second, a request for a secure command to unlock the tag for a limited number of authentication-and-tamper-sensor requests. All other stimuli result in the response LOCKED.

\subsubsection{Communication Baud Rate (9600/1200)}

The tag will accept stimuli and transmit responses at one of two baud rates, 9600 bits per second or 1200 bits per second. The selection between the two baud rates is made by a secure stimulus. The default baud rate is 9600 but may be changed during the initialization process. The baud rate is available as part of the tag's response to a request for tag identification parameters.

\subsubsection{Analog Measurement (enabled/disabled)}

The tag can make a single analog measurement. This ability can be turned on or off through the use of the secure stimulus, which is initialized when the encryption key is installed. The analog measurement status (enabled or disabled) is available as part of the tag's identification; however, the actual analog measurement is encrypted as part of the tamper-sensor response.

\subsubsection{Control Bits (high/low)}

The tag has two digital output bits that control tag peripherals. These bits are set (high), or reset (low) by secure stimuli. The tag also has two digital input bits that monitor tag peripherals. The status of both input bits and output bits is available in encrypted format as part of the tamper-sensor response. Output bits are initialized when the encryption key is installed.

\subsubsection{Sleep Mode Enable (disabled/enabled)}

If enabled, the tag will awake to any stimulus and respond appropriately. After responding, the tag will wait a few seconds for a subsequent stimulus and, if none is forthcoming, the tag will return to its sleep mode (low-power 
mode). A secure stimulus is required to change the sleep mode enable, initialized at the time the encryption key is installed. The status of the sleep mode enable is available as part of the tag's identification.

\subsubsection{Secure Function}

Secure commands are useed to set the internal parameters and functions of a tag. These parameters determine how the tag responds to external events and whether or not its security functions are active.

A secure function requires the user to enter data that will match a pattern after being encrypted. This pattern comprises several zeroes, a counter, and a two-digit code that specifies the secure function. When this pattern is matched, the tag performs the specified secure function and advances the counter that is used in the pattern matching. It also sends an acknowledgment message, which informs the user that an unspecified secure function has been performed. Because the counter is advanced on each successful command, each command will work only once.

\subsection{Program Structure and Specification}

A user-friendly program for tag communication was developed with a screen menu based on Windows for $\mathrm{C}$ and Windows for Data. Appendix A gives detailed information on the design of the program structure and specifications; Appendix B shows the program flow chart; and Appendix C lists all of the source files and other files related to the program.

The tag user interface program can be installed on any IBM-compatible PC (386 or 486) under standard DOS or Windows environments, version 3.1 (Windows) or later. The modem connected to comport COM1 communicates with the Qualcomm network management computer (NMC) at 2400 baud.

The main menu of the tag user interface includes four submenus: View, Send, Status, and Tables.

The main program will perform some initialization functions, dial the Qualcomm NMC, $\log$ on to the NMC, get the tag status, authenticate encrypted responses, and provide other information for the View submenu. 
The main program anl_tag.exe first calls title 0 for display of the title of the tag user interface, as shown in Fig. 7 . It then sets baud rate, NMC time out, and other parameters. The screen (Fig. 8) shows progress information, dialing into Qualcomm and logging on the NMC when the main program calls dial_pc.exe and log_on.exe. The screen will also indicate whether there are messages waiting from the tags. If there are tag messages, the main program will call get_msg.exe to authenticate encrypted responses and get tag status. The information is then ready for display under the View submenu.

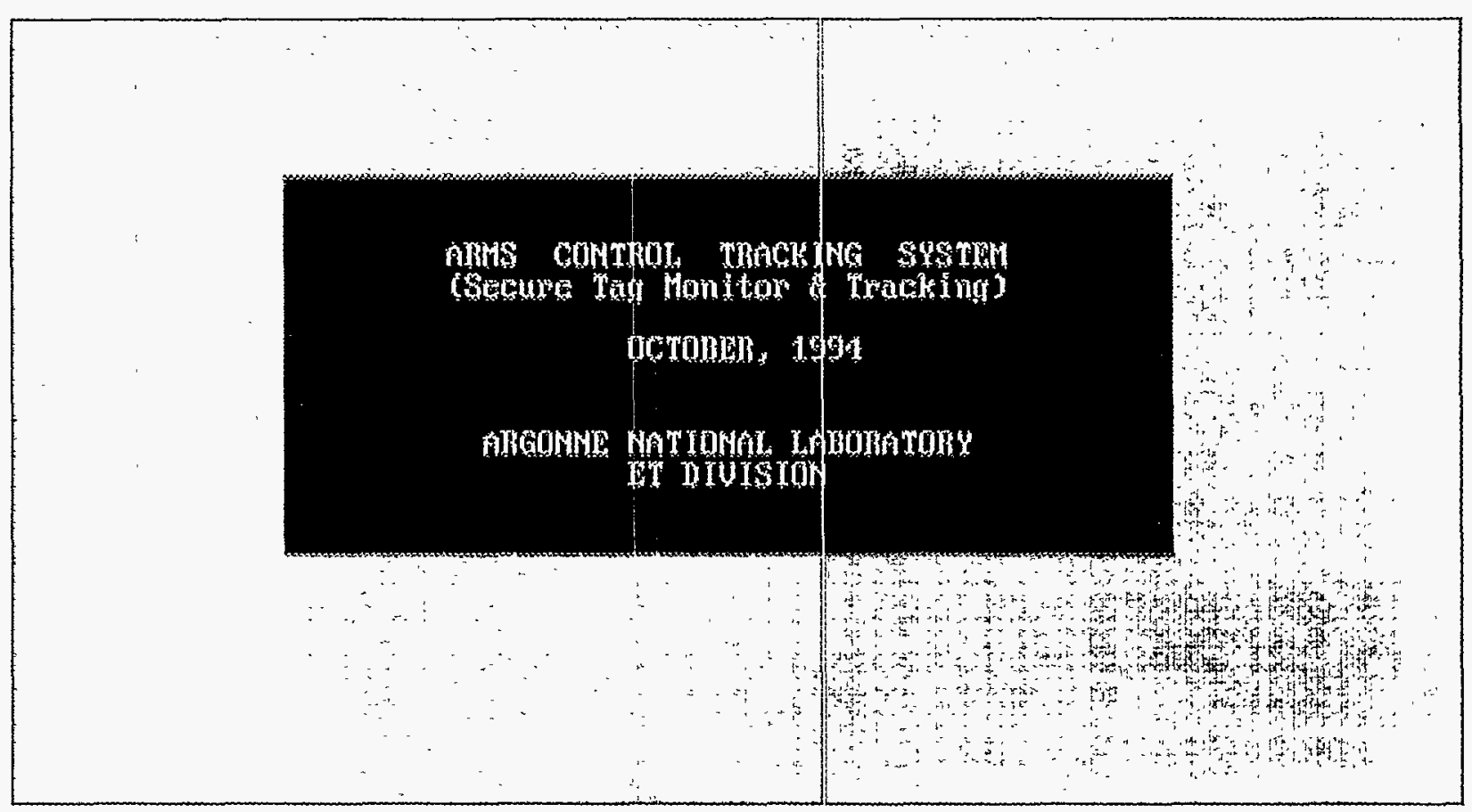

Fig. 7. Title screen of tag user interface 


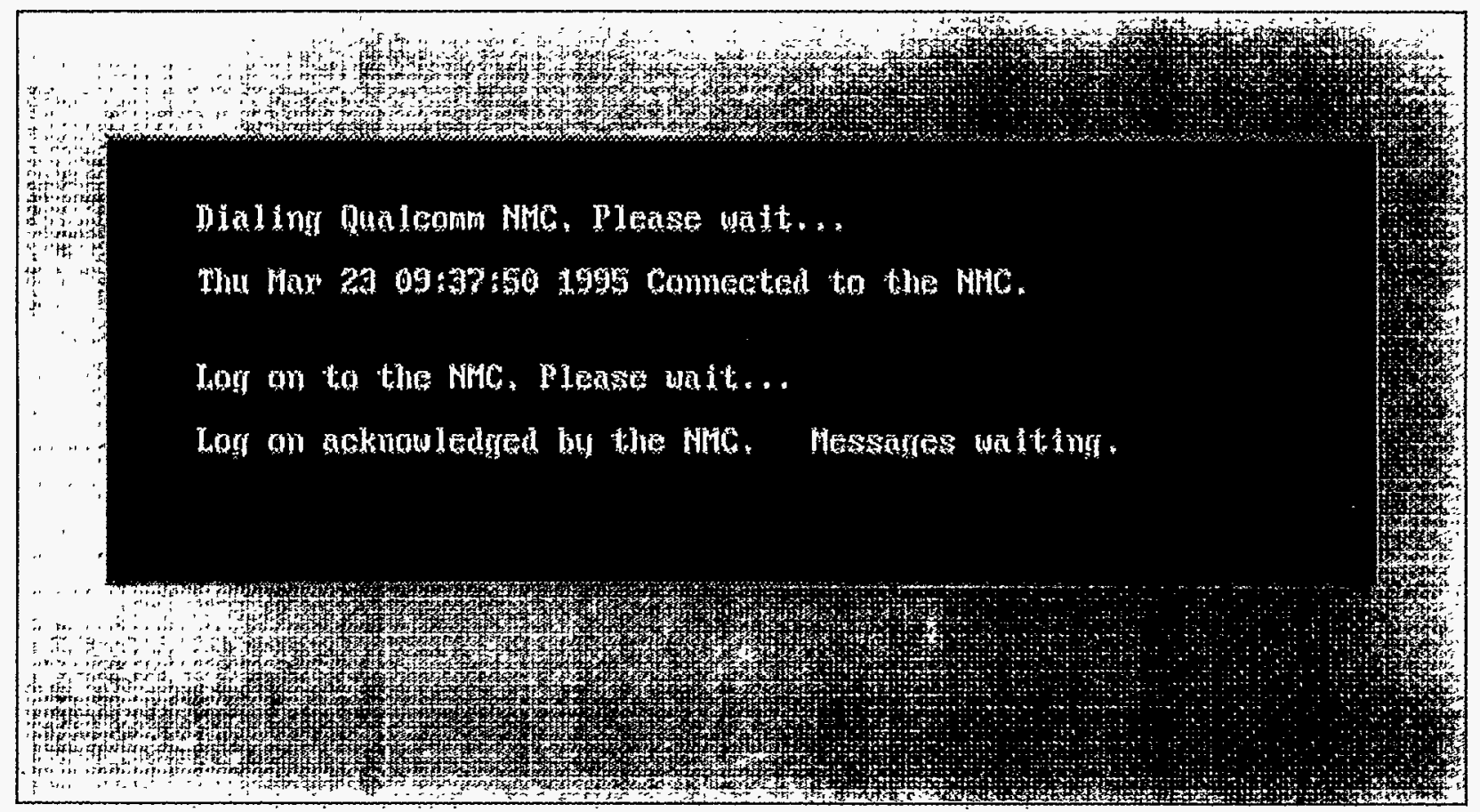

Fig. 8. Screen for dialing Qualcomm and logging on to NMC

The View submenu displays all necessary information (MCT and $\mathrm{OBC} / \mathrm{TAG}$ communication data) on the screen, receives message packets from the NMC via get_msg.exe, extracts messages (authenticating encrypted responses), and exits to the previous menu. The main display screen shows the last eight messages from tag responses and MCT data (ID, position, and time), tag data (message time, ID, stimulus key and challenge, tag response information, tag status, and tamper status), as shown in Fig. 9. 


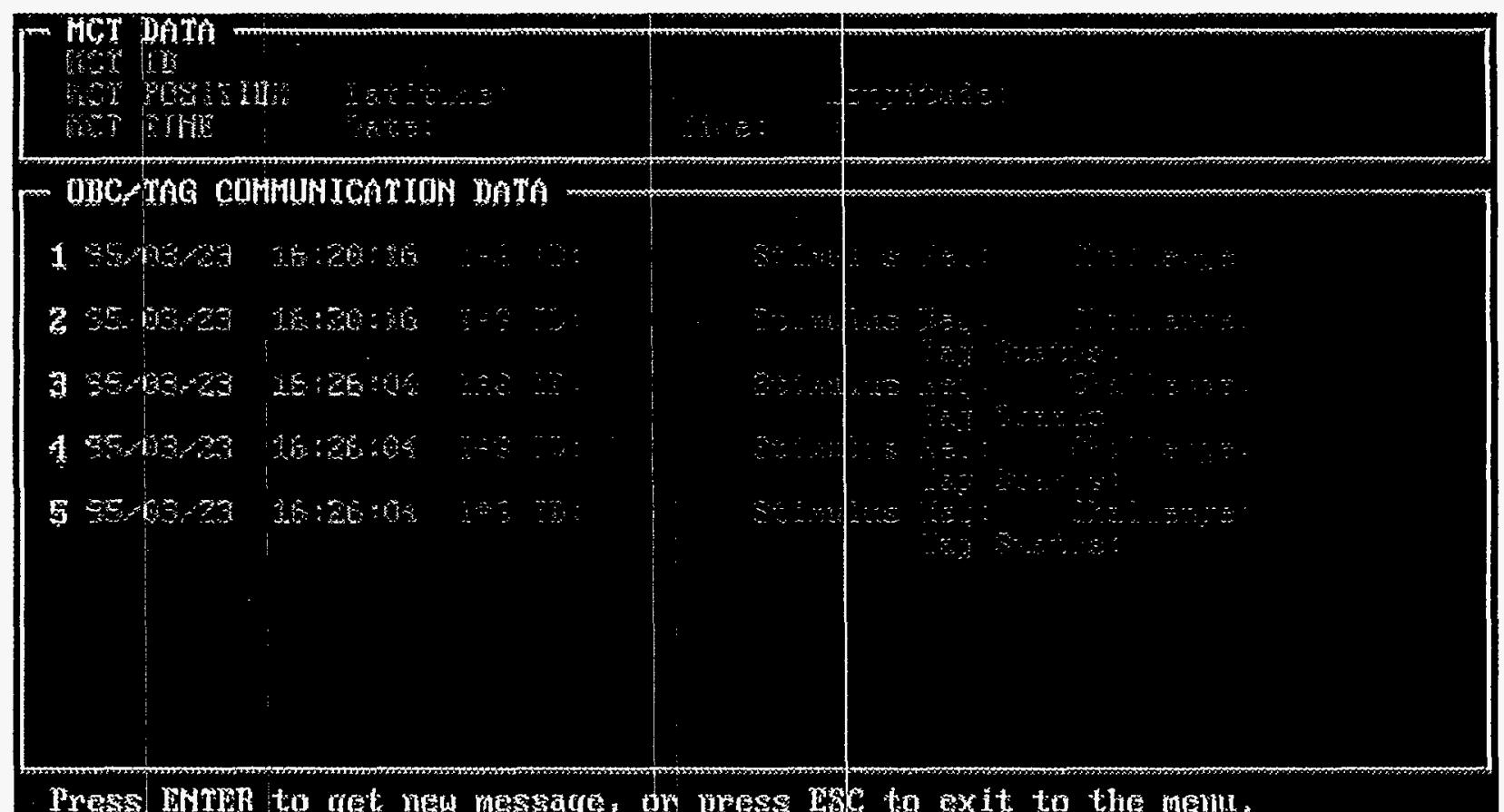

Fig. 9. Display screen of MCT and OBC/TAG communication data

The Send submenu executes stimulus sequences and sends secure commands and text data messages to the tags.

The Execute submenu is a pull-down menu under the Send submenu. The Execute submenu generates a randorn stimulus for each tag message (Authentication), sends and stops acquire-data sequences (Acquire Data), sends and stops verification sequences (Verification), and generates immediate-stimulus messages for individual tags, or all tags in the ANL segment (a segment comprises all tags with the same MCT address). Submenus under the Execute submenu are all pull-down type (Fig. 10). When performing the desired operations, the program, based on the function selected, generates a specific string of numbers to be sent to the $\operatorname{tag}(\mathrm{s})$. 


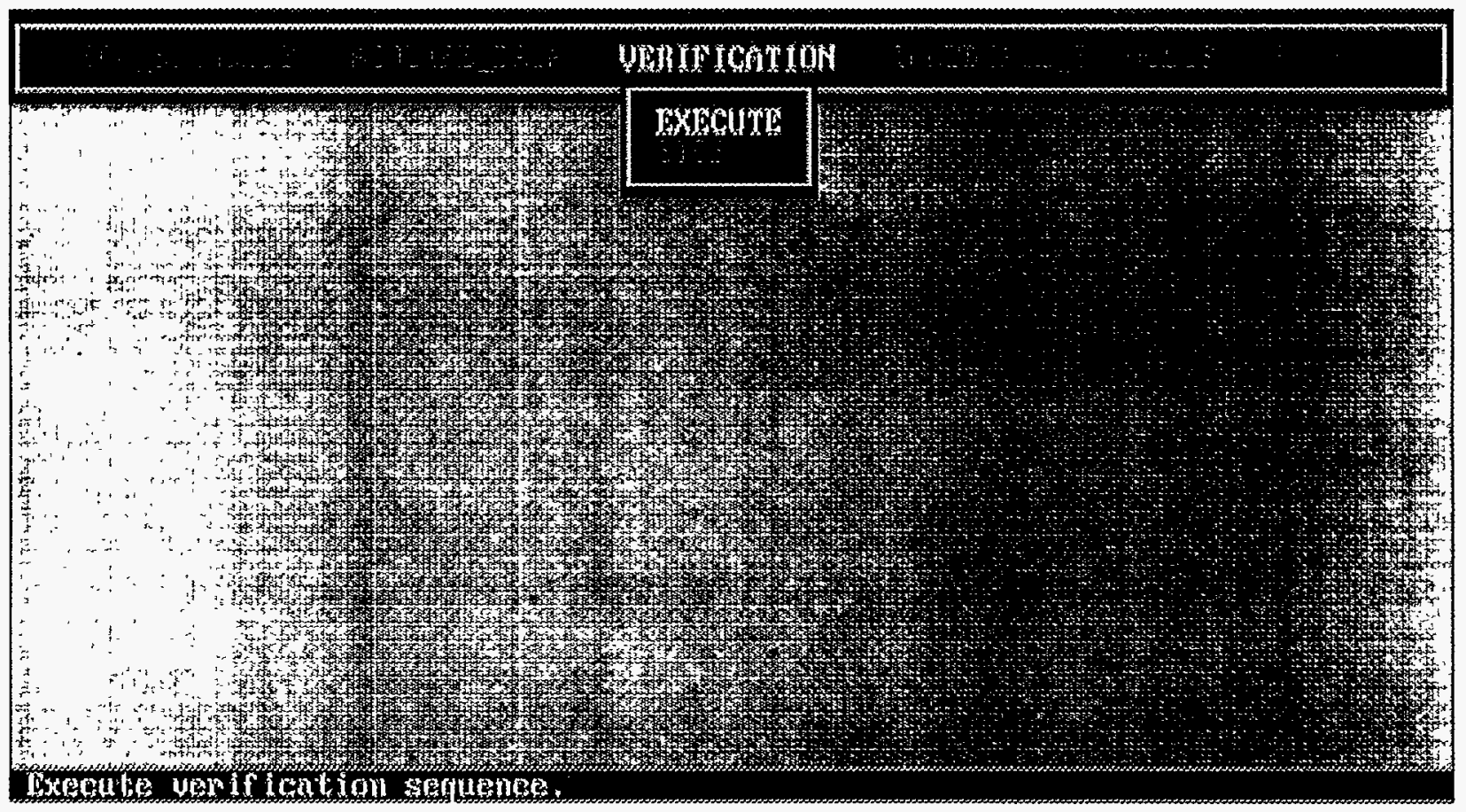

Fig. 10. Screen of Execute submenu

The Secure Command submenu is a function under the Send submenu. First, this function asks the user to select a tag ID from a list of choices displayed on the screen. Then the program automatically checks the status of the selected tag and indicates it on the screen. If the tag status data is not available, the program will send a status request for this tag. If the tag is locked, the program will select a secure function to unlock the tag, and send a request for the tag status. If the tag status is normal, the program will ask the user to select a secure-function command from a list on the screen by pressing the F2 key (see Fig. 11). The list contains 29 secure-function commands (Table 1), including control options and secure-functions, as described above. If the user'selects a dangerous command, the program will ask the user to enter an authorizing password. For several commands, the program will ask the user to input trend limits and trend window limits. Then the program will generate a message string for the selected secure function and send it to the selected tag. 


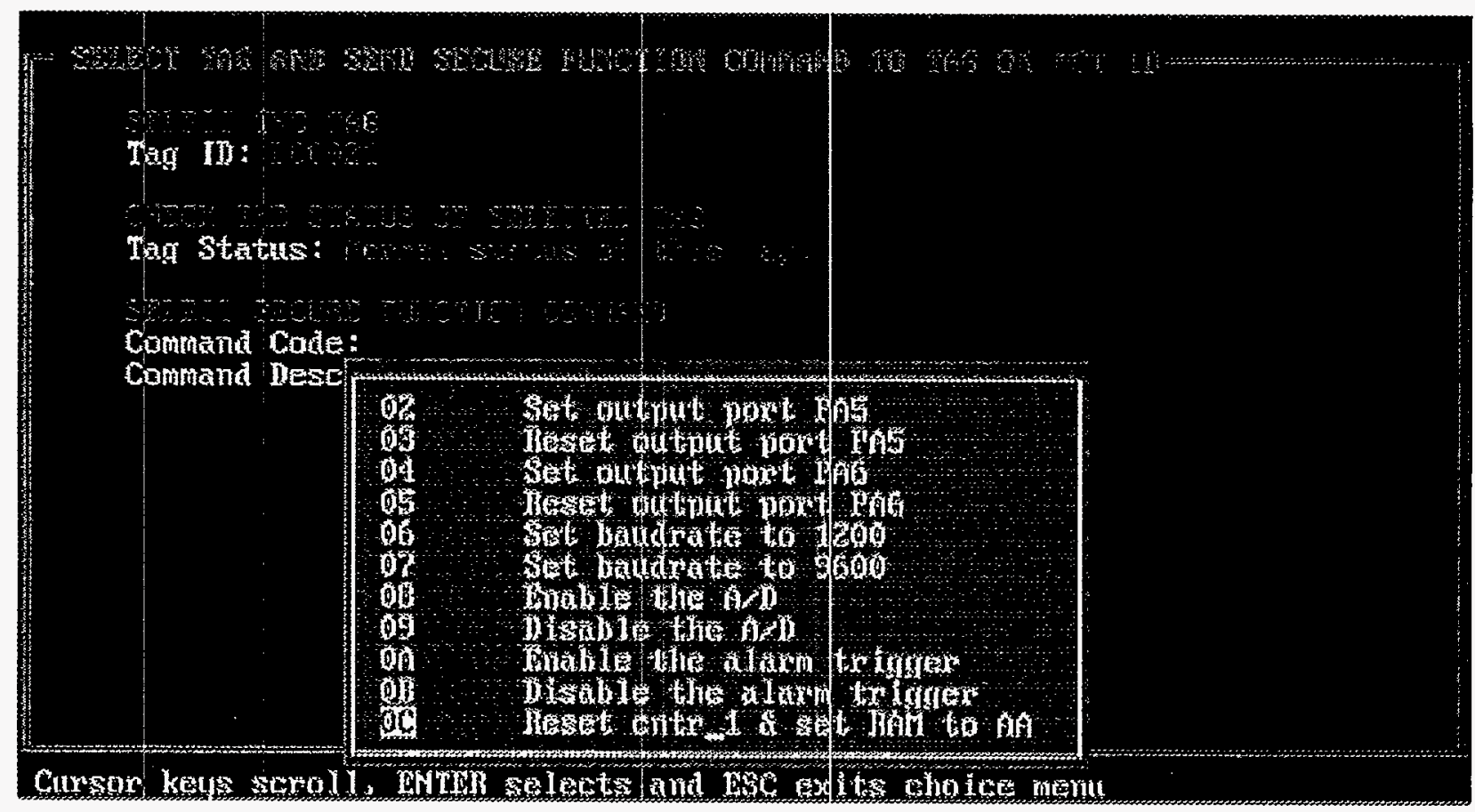

Tht ID: poote 1

Tht SThTu: Nomal sitatus of this tinf .

COHATHD COMT: QC

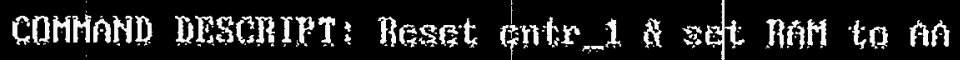

Sending the secume canmand to the tary bobo21.

Plenge ualt...

Prese any key to raturn to the mand.

Fig. 11. Screens of Secure-function command selections 
Table 1. List of Secure-command functions

\begin{tabular}{|c|c|l|}
\hline Number & Code & \multicolumn{1}{|c|}{ Descriptions } \\
\hline 1 & 00 & Increment tag counter_3 \\
2 & 01 & Unlock tag for 10 commands \\
3 & 02 & Set output port PA5 \\
4 & 03 & Reset output port PA5 \\
5 & 04 & Set output port PA6 \\
6 & 05 & Reset output port PA6 \\
7 & O6 & Set baudrate to 1200 \\
8 & O7 & Set baudrate to 9600 \\
9 & O8 & Enable the A/D \\
10 & 09 & Disable the A/D \\
11 & OA & Enable the alarm trigger \\
12 & OB & Disable the alarm trigger \\
13 & OC & Reset cntr_1 \& set RAM to AA \\
14 & OD & Enable sleep mode \\
15 & OE & Disable sleep mode \\
16 & B0 & Disable the tag's lock \\
17 & B1 & Enable the tag's lock \\
18 & B2 & Disable the A key encrypter \\
19 & B3 & Enable the A key encrypter \\
20 & B4 & Erase the A key encrypter \\
21 & B5 & Reset counter_3 to zero \\
22 & B6 & Disable the D\&F key encrypter \\
23 & B7 & Enable the D\&F key encrypter \\
24 & C0 & Reset alarms \& EEPROM cntr_5 \\
25 & C1 & Reset RAM cntr_5 \\
26 & C2 & Set fiber trend limit \\
27 & C3 & Set pressure trend limit \\
28 & C4 & Set fiber window limits \\
29 & C5 & Set pressure window limits \\
\hline
\end{tabular}


The Status submenu allows users to check tag status from the screen. Individual Tag Status is a Perform-function that displays a selected tag status (including EO, FO, F1, F2, and F3 Status), tag age, and MCT address (Fig. 12). The ANL Segment Status is a Perform-function that displays the status of all tags in the ANL segment. It will include MCT data and each tag's ID, segment status and age, and tag tamper status and age (Fig. 13).

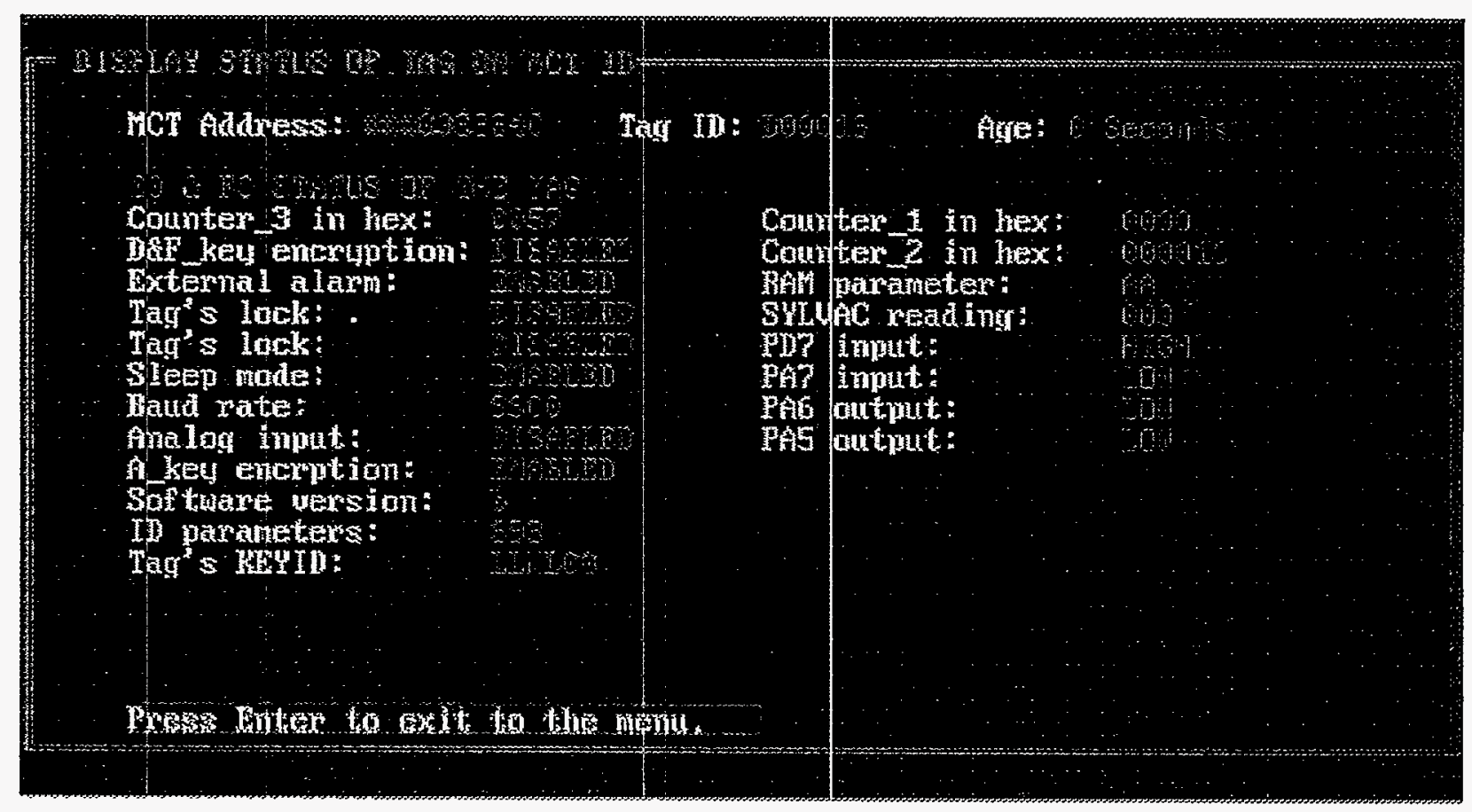

Fig. 12. Individual tag status screen 


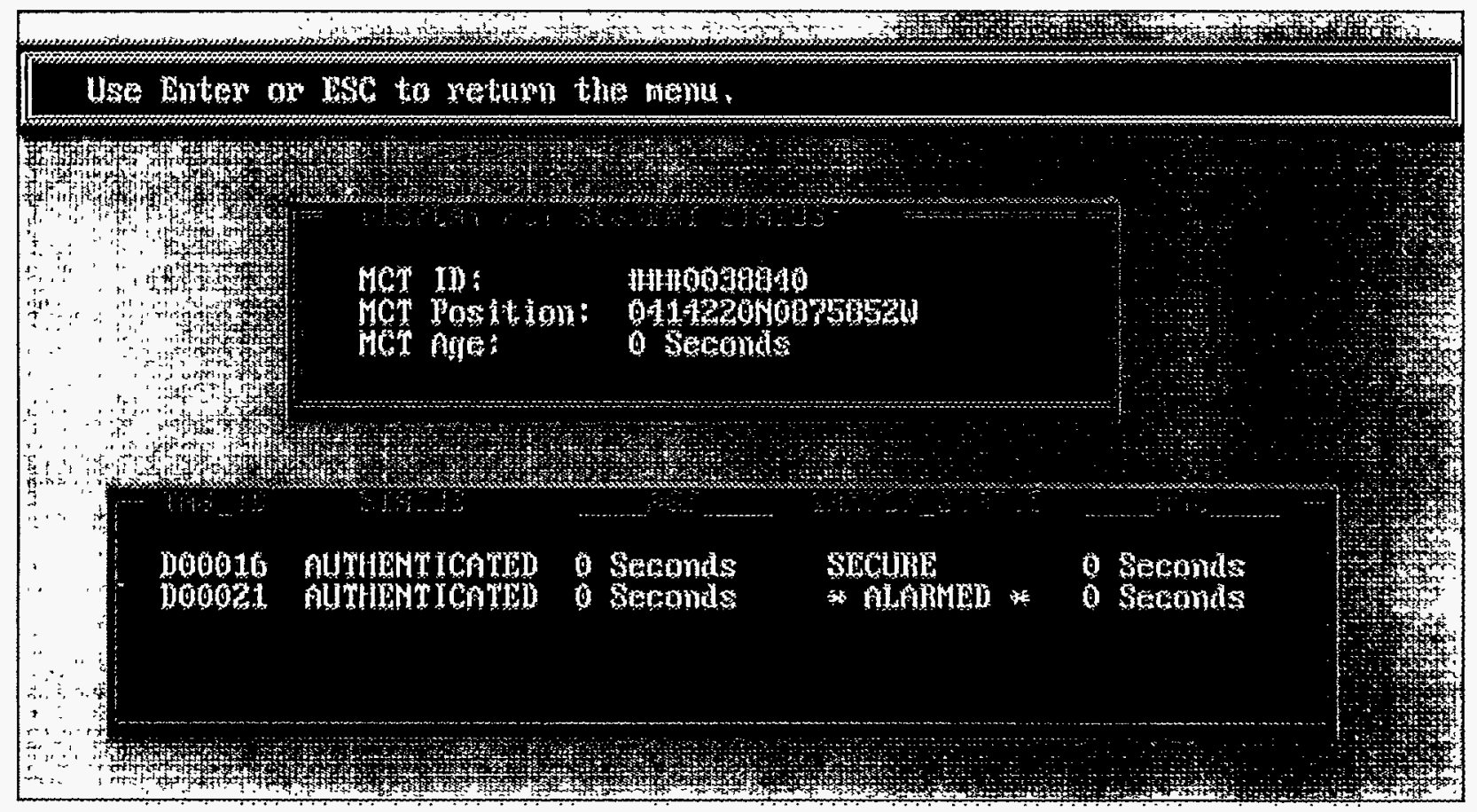

Fig. 13. Segment status screen

The Tables submenu includes Send Table and Edit Table functions (Tag ID Table, Authentication-Sequence Table, Acquire-Data-Sequence Table, Verification Table, and Tag Stimulus Table).

The Tag ID Table lists the tags, their ID numbers, and mode number. This table will be called in each submenu and several functions to select tag ID. The Authentication-Sequence Table lists frequency, mode number, authentication keys and challenges for random stimulus. The Acquire-DataSequence Table lists frequency, mode number, tag ID authentication keys and challenges. The Verification Sequence Table lists frequency, mode number, tag ID, authentication keys and challenges, and expected responses.

The Send_Tables is a pull-down submenu under the Tables submenu. The user can select commands from this menu (Fig. 14). The Edit_Table is another pull-down submenu under the Tables submenu. It allows users to select a table and edit it. Edit functions include adding, deleting, and replacing table contents via function keys (Fig. 15). 


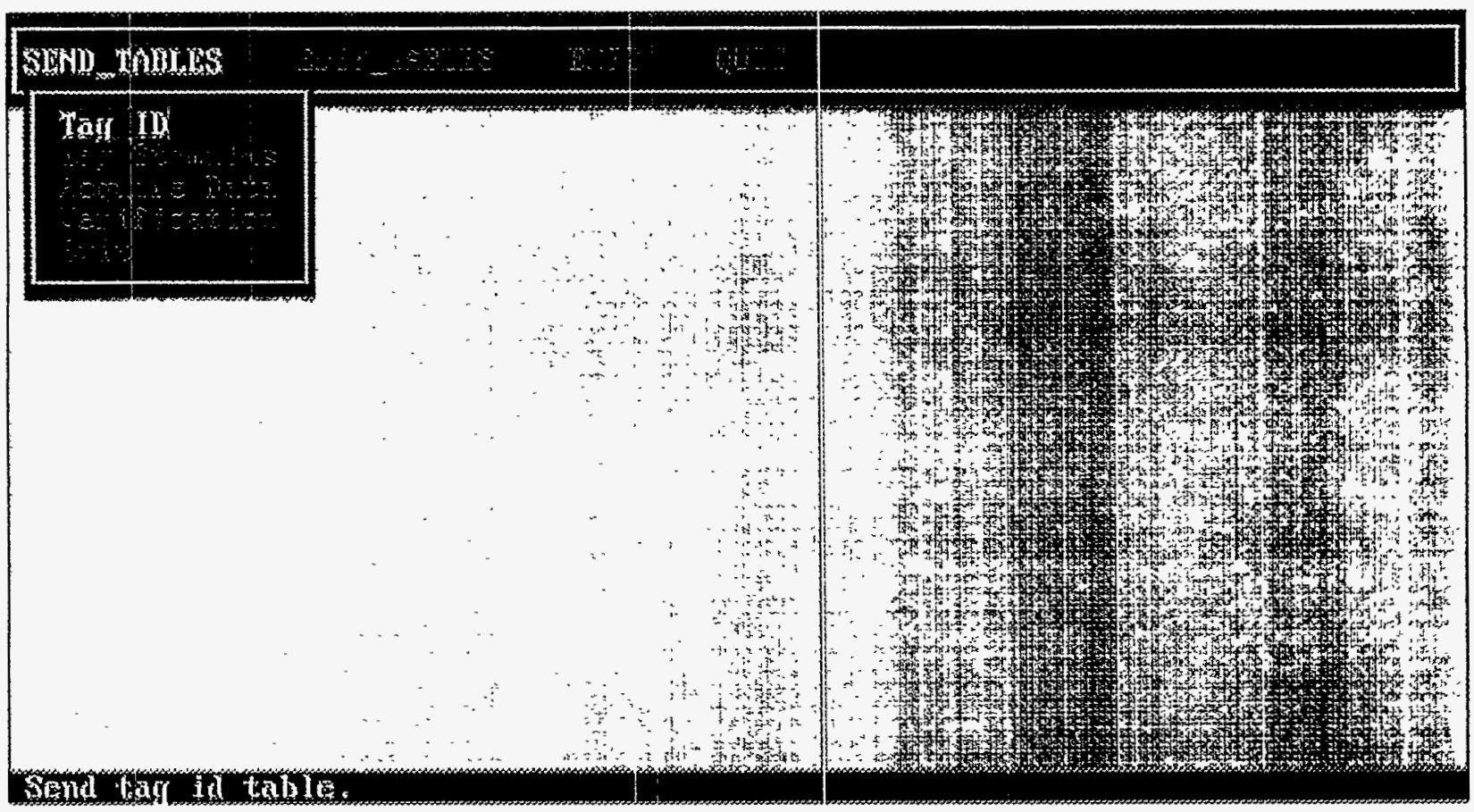

Fig. 14. Send_table submenu screen

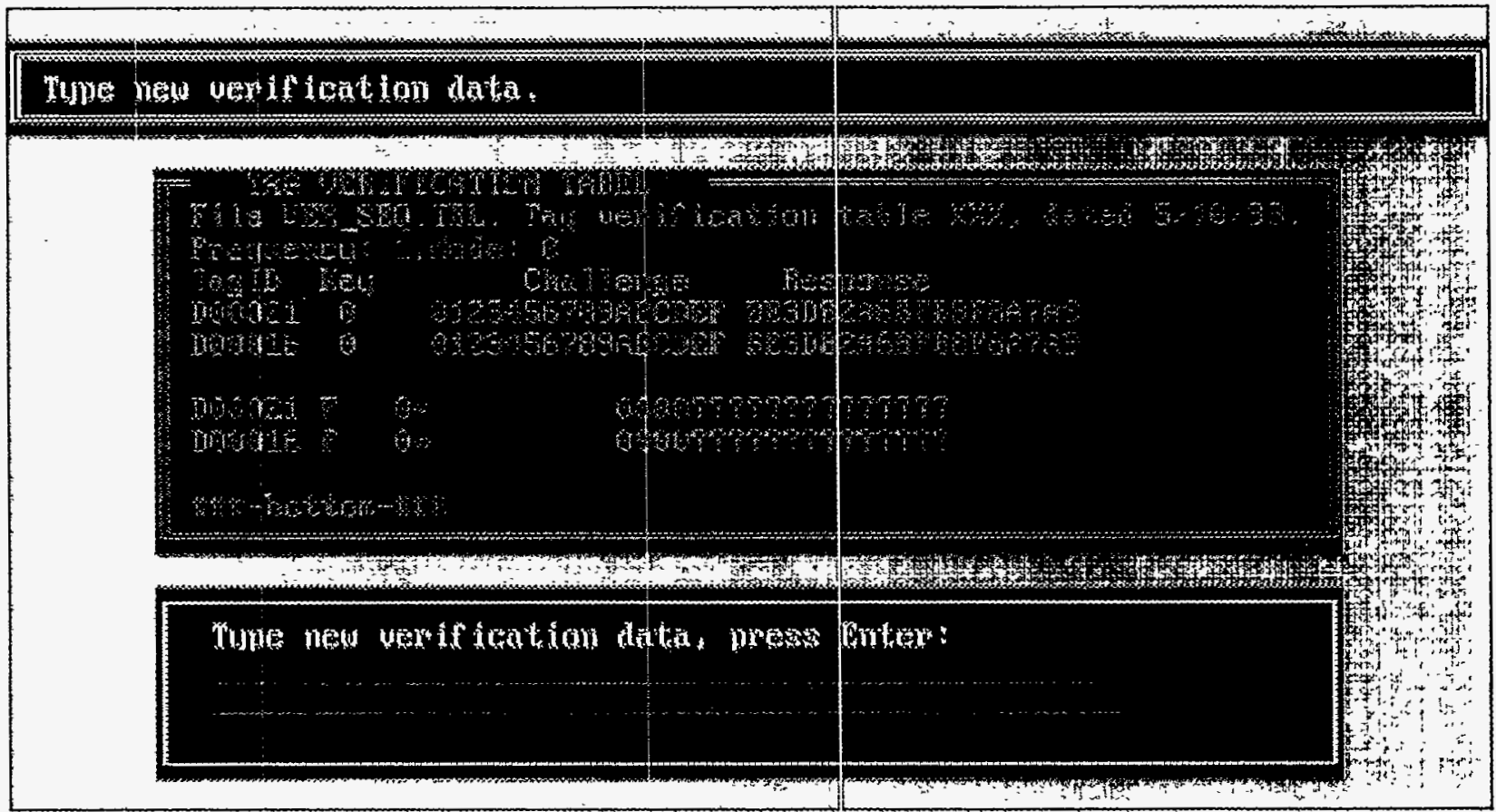

Fig. 15. Edit_table screen

In the main menu or any level submenu, users can select a Quit function to exit the tag user interface program and $\log$ off the NMC. Figure 16 shows a normal status for logoff. 


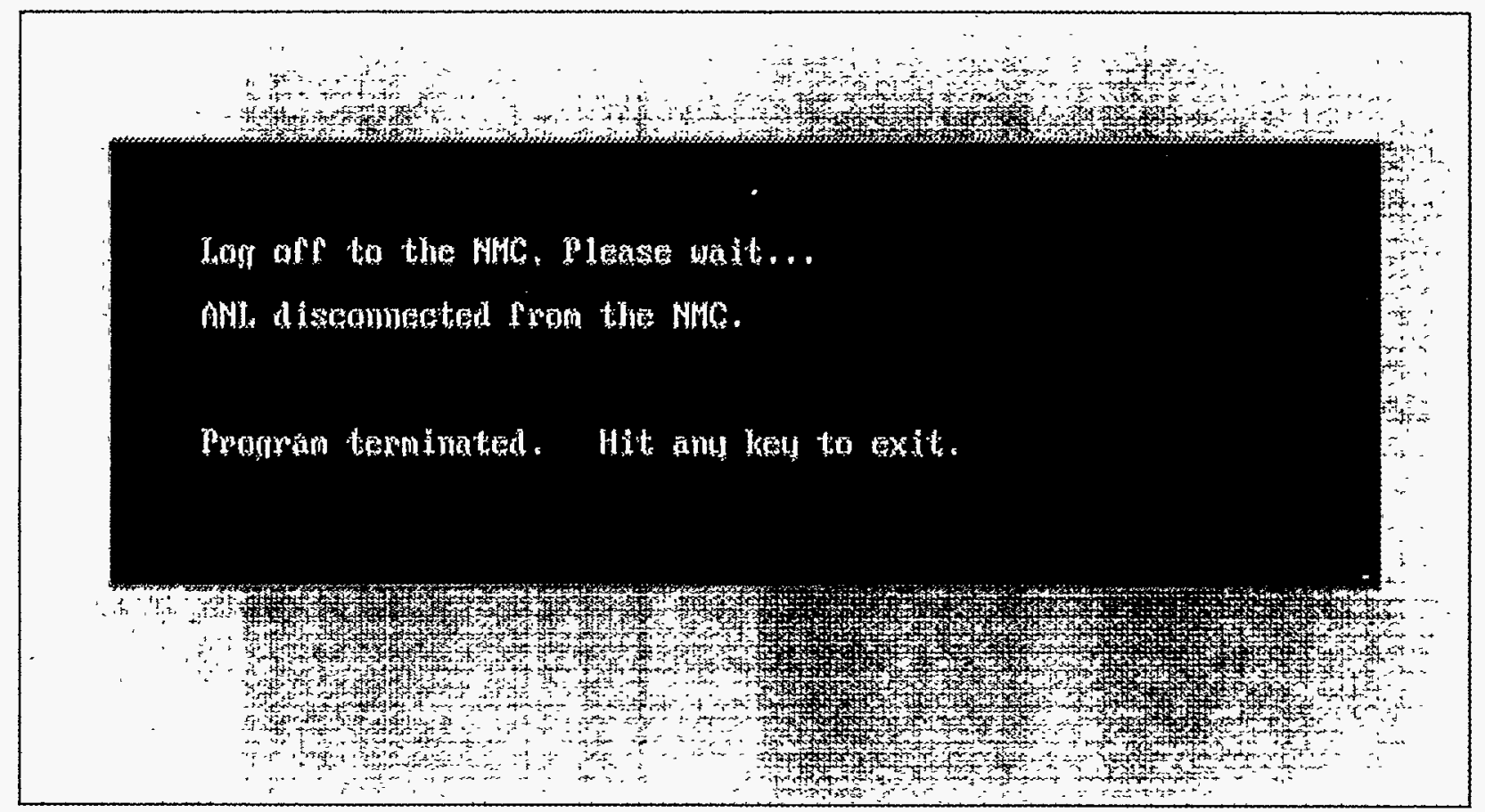

Fig. 16. NMC log off screen

Log files (see Appendix C) will record all data and message transfer between users and the $\mathrm{OBC} / \mathrm{tag}$.

\section{Incorporating Tag User Interface into TRANSCOM}

One of the main objectives of the Warhead Dismantlement/Special Nuclear Materials Control Program is to incorporate secure-electronic-tag technology into DOE's TRANSCOM for tracking radioactive material.

\subsection{TRANSCOM Tracking System}

TRANSCOM is DOE's transportation, tracking, and communications system for unclassified shipments of transuranic waste, spent fuel, high-level waste, and other high-visibility shipping campaigns as determined by DOE. It functions by using a commercial satellite tracking and communication system, computerized information processing systems, and personal computers supplied and operated by authorized users. 
TRANSCOM provides near real-time tracking of and direct communications with high-visibility shipments, oversight of shipments of potentially harmful materials, planning for the receipt of materials at predetermined destinations, and emergency response and guideline capabilities. Information provided through this existing technology includes vehicle location $(3,100$ computer maps), shipment status (e.g., loaded, empty, truck, rail, normal conditions, off-normal conditions, etc.), shipment information (e.g., material identification, hazard class, fissile class, etc.), emergency response information, shipment route, advanced notification, report(s), and two-way communications.

The system consists of satellite communications, data base management, computer networks, and commercial telecommunications services that are integrated and controlled from the TRANSCOM Control Center (TCC). The TCC is managed by ORNL and has been in service since 1989.

TRANSCOM customers include DOE, ANL, various shippers and receivers, vehicle operators, and other government agencies (OGA). Figures 17 and 18 illustrate data transfer and message services of TRANSCOM. 


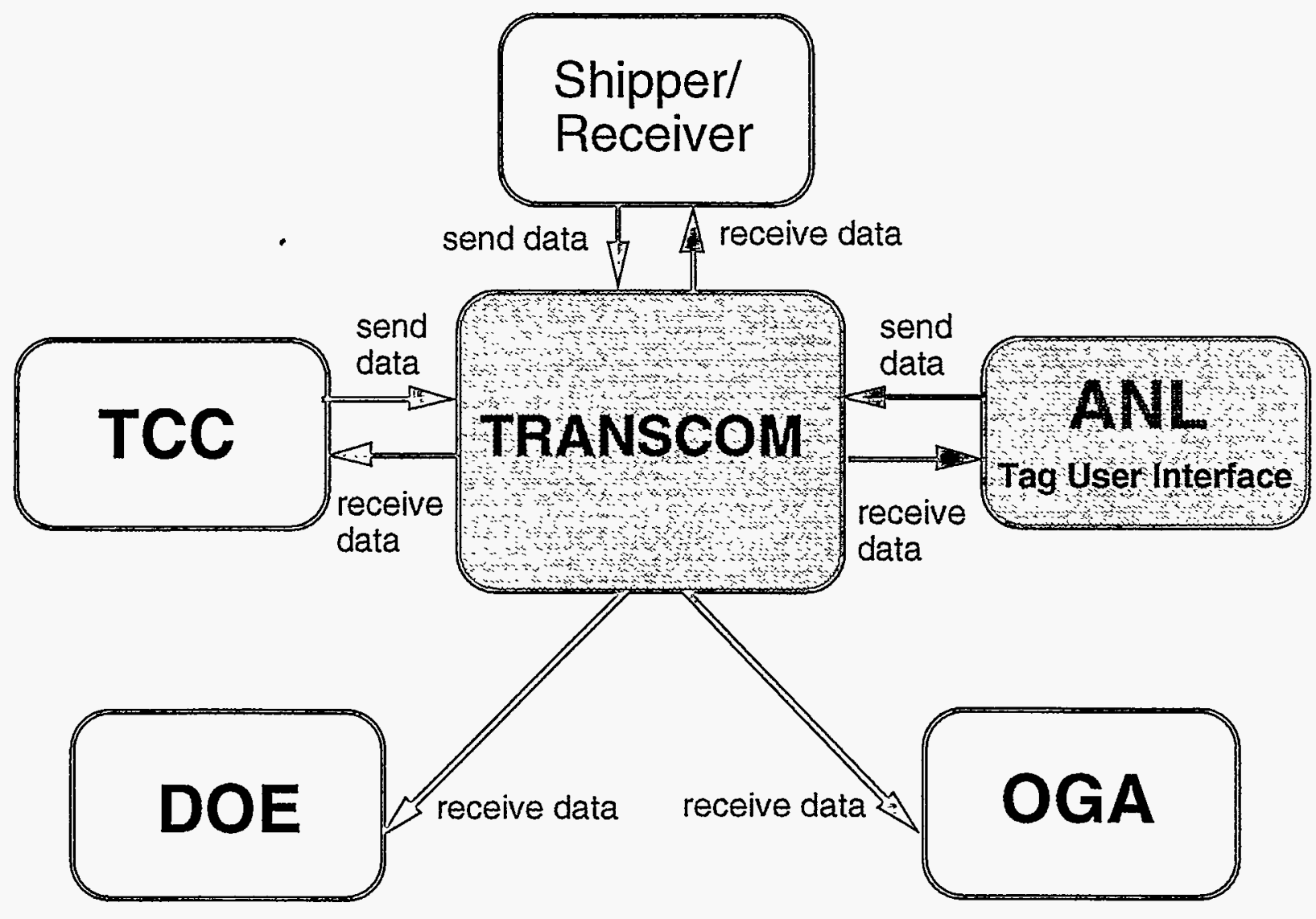

Fig. 17. TRANSCOM data transfer services 


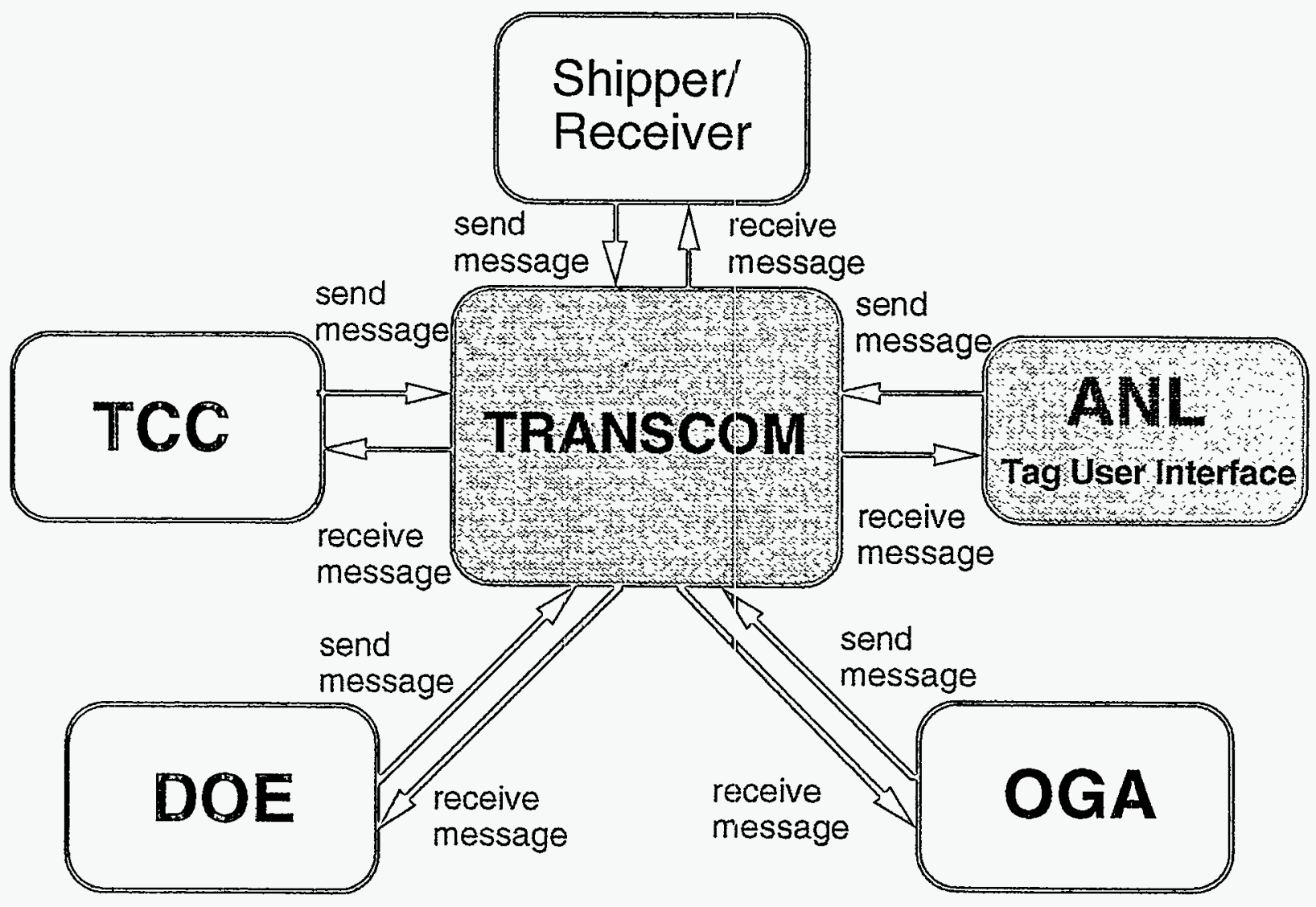

Fig. 18. TRANSCOM message services

TRANSCOM is currently being converted from a DOS-based application to a Microsoft Windows-based application by Martin-Marietta at ORNL. The new software, which is expected to be received during fiscal year 1995, will include the existing functionality and will add enhanced (vector scan) map graphics, improved communications capability, extended error checking, and LLNL secure-tag communication windows, among other system improvements. Differences in software technologies prevent enhancing the current TRANSCOM software suite and porting the enhancements to the upgraded system. The TRANSCOM upgrade will be Windows-compliant so that it will co-reside with various user cornfort modules, use high memory, and minimize the use of low memory. Further, the TCC will utilize the Oracle data base manager and AT\&T release 3 UNIX OS (SCO UNIX 3.2.4.2). This software configuration will receive current vendor support, including revisions, bug-fixes, and enhancements. 


\subsection{Incorporating Tag User Interface into TRANSCOM}

An effort is being made at ANL to incorporate the secure-tag user interface into TRANSCOM by collaborating with ORNL. The features of the tag user interface, discussed in Section 3, will be ported to the upgraded TRANSCOM software suite.

The tag control functions will be integrated into the upgraded TRANSCOM. The operation of the current TRANSCOM will not be affected by this effort. The initial effort will provide minimal tag functions for a proofof-concept test in the U.S. for the ANL Arms Control Program sponsors at DOE NN-20. Upon completion of the proof-of-concept test, additional effort will be expended to expand the tag screens to include a full set of tag functions. Specifically, the following tasks are envisioned as needed for the initial test:

- Update the UNIX server programs to communicate with the tags.

- Update the UNIX data base to store the tag messages.

- Update the UNIX TSH (communications programs) to transfer data to remote user PCs (client).

- Update the client PC programs to query tag data from the server (communications to client PC).

- Develop or integrate tag screens into the client's software windows.

- Display the icon for the location of the transponder. It is desirable to have more than one tag connected to a transponder.

A completed working version of TRANSCOM, with ANL secure-tag graphics enhancements, will provide two-way communications between TRANSCOM and the tag. The tag status will be queried by and reported to TRANSCOM. It will be possible to expand the geographic area of coverage of TRANSCOM. Secure-tag tracking and monitoring will require input of maps of Europe and western Asia.

\section{Current and Future Applications}

Secure-electronic-tag technology and its integration into DOE's TRANSCOM will provide current and potential future applications in broader systems to monitor and track items in storage in a specific location, and while they are in transit. 


\subsection{Warhead Dismantlement and Nonproliferation Treaty}

Secure-electronic-tag technology and its integration into DOE's TRANSCOM will be applied to monitoring and tracking the locations, movements, and operational activities of warheads and fissile materials in either the field or stockpiles in the former Republics of the Soviet Union and in Russia.

The development of secure-tag technology and its commercialization will allow authorized foreign governments to monitor movements without accessing secure military systems. The OPEN ${ }^{1}$ nature of this system makes it a desirable commodity.

\subsection{Tracking U.S.-Origin Nuclear Materials in Europe}

The technology developed under this project will also be applied in tracking the current location and status of all U.S.-supplied weapons-grade nuclear materials in foreign countries, especially in the European atomic energy community (EURATOM) where much of this material has been delivered.

DOE's system for tracking the current location and status of all nuclear materials of U.S. origin that are supplied to foreign countries is limited, because the United States does not require foreign countries to report the location of U.S. materials.

The application of secure-tag technology will overhaul and strengthen the tracking system for U.S. officials who are monitoring weapons-grade nuclear materials overseas to ensure that nuclear nonproliferation standards are met.

\subsection{Intelligent Transportation Systems}

Intelligent Transportation Systems (ITS) involve a range of advanced technologies and system concepts that, when used in combination, can improve mobility and transportation productivity, enhance safety, maximize

\footnotetext{
${ }^{I}$ An OPEN system utilizes commercial digital computers and modems to interface commercial satellite and communication systems with commercial telecommunications technologies. System access is limited through the use of custom software with a controlled distribution and requires a unique user ID, password, and mobile communication terminal ID(s).
} 
the use of existing transportation facilities, conserve energy resources, and reduce adverse environmental effects.

The technology developed in this project can be easily converted to monitoring and tracking ground vehicles, either army combat vehicles or commercial vehicles. The potential application of this technology to highway traffic tracking systems will support a comprehensive traffic and transit information service, and will be of assistance to highway traffic control and management.

Secure-tag technology can be applied to electronic clearance of commercial traffic crossing the U.S.-Mexican border, in support of the North American Free Trade Agreement (NAFTA). The integration of existing advanced technologies will increase commerce and also prevent overweight, unsafe, or improperly registered vehicles from entering the U.S. ORNL, ANL, and other partners have jointly proposed international border electronic clearance by using the smart tag to track the movement of commercial traffic at highway crossings along the U.S.-Mexico border.

\section{Conclusions}

This report summarizes and documents ANL's effort in developing a tag communication user interface that provides a tag monitor and communication tool with enhanced, user-friendly computer screen displays. The new interface represents the first step in updating the TRANSCOM tracking system by incorporating a tag communication screen menu into the main menu of the TRANSCOM User Program. The new system will include enhanced graphics and user capabilities and will utilize the Windows 3.1 environment and extended memory management.

The completion of a working version of TRANSCOM ANL secure-tag graphics enhancements, in collaboration with ORNL, will strongly support DOE headquarters Warhead Dismantlement/Special Nuclear Materials Control initiatives. The use of commercial satellite technology will allow a user to monitor and track the movements and operational activities of treaty-limited items and transportation vehicles throughout eastern Europe and the former USSR. It will also be applicable in other areas and will greatly enhance the marketability and usefulness of TRANSCOM. 


\section{Acknowledgments}

This work was performed under the sponsorship of the U.S. Department of Energy, Office of Nonproliferation and National Security (NN1) and Office of Research and Development (NN-20), through the project of Warhead Dismantlement/Special Nuclear Materials Control Program (AL500).

Additional thanks to Mr. Robert Rumble of LLNL and Dr. Glen Harrison of ORNL for their cooperation in this work. 


\section{References}

Gritton, D. G., Doty, M. A., Sutton, G. L., and Riley, M. O., 1993, Tag Technology R\&D Final Report: Secure Electronic Tags, Report UCRL-ID1 12709, March 1993, Lawrence Livermore National Laboratory, University of California, Livermore, CA 94551. 


\section{Appendix A: Tag User Interface Program Specifications}

\subsection{Main menu}

Dial QualComm.

Log on the Network Management Computer (NMC).

Initialization functions.

Get tag status.

Authenticate tag response if there are any messages waiting. Initialize the main menu of tag user interface program.

\subsection{View}

View tag message menu. Receive/view message data.

1.1 Display Tag Information

Displays MCT position and time data.

Receive tag messages.

Extract tag messages.

Display OBC/tag communication data.

View tag response.

Indicate tag status.

1.2 View of Text Data

Receive/Read text messages (currently not available).

\subsection{Exit}

Exit to previous menu.

\subsection{Send}

The menu for sending message to tags. Send string to tags.

\subsection{Execute}

Initialize the menu for executing stimulus.

2.1.1 Authentication

Execute random authentication sequence.

2.1.2 Acquire-data

Execute acquire-data sequence.

2.1.2.1 Send

Send acquire-data sequence.

2.1.2.2 Stop

Stop acquire-data sequence.

2.1.3 Verification

Execute verification sequence.

\subsubsection{Send}


Send verification sequence.

2.1.3.2 Stop

Stop verification sequence.

2.1.4 Immediate Stimulus

Execute immediate stimulus.

2.1.4.1 Individual tag stimulus

Send single tag stimulus from keyboard.

2.1.4.2 ANL segment

Execute immediate stimulus to each tag.

2.1.5 Exit

Exit to previous menu.

2.2 Secure Command

Select tag and check tag status.

Lock and unlock tag.

Select and send secure commands.

2.3 Text Message

Edit and send text data to tags (currently not available).

2.4 Exit

Exit to previous menu.

2.5 Quit

Log off the NMC and exit to DOS.

\subsection{Status}

Check tag status menu.

3.1 Individual Tag Status

Select and view detailed status of individual tag.

3.2 ANL Segment Status

Display MCT address and age.

View ANL segment status.

Indicate tag tamper status.

3.3 Exit

Exit to previous menu.

3.4 Quit

Log off the NMC and exit to DOS.

\subsection{Tables}

Tag table menu.

4.1 Send Tables

Send tables to tags.

4.1.1 Tag ID 
Send tag id table.

4.1.2 Tag Stimulus

Send tag stimulus table.

4.1.3 Acquire-data

Send acquire-data table.

4.1.4 Verification

Send verification table.

4.1.5 Tag Stimulus

Send tag stimulus table.

4.1.6 Exit

Exit to previous menu.

4.2 Edit Tables

4.2.1 Tag ID

Edit tag id table.

4.2.2 Tag Stimulus

Edit tag stimulus table.

4.2.3 Acquire-data

Edit acquire-data table.

4.2.4 Verification

Edit verification table.

4.2.5 Tag Stimulus

Edit tag stimulus table.

4.2.6 Exit

Exit to previous menu.

4.3 Exit

Exit to previous menu.

4.4 Guit

Log off the NMC and exit to DOS.

\subsection{Quit}

Log off the NMC and exit to DOS. 


\section{Appendix B: Tag User Interface Program Flow Chart}

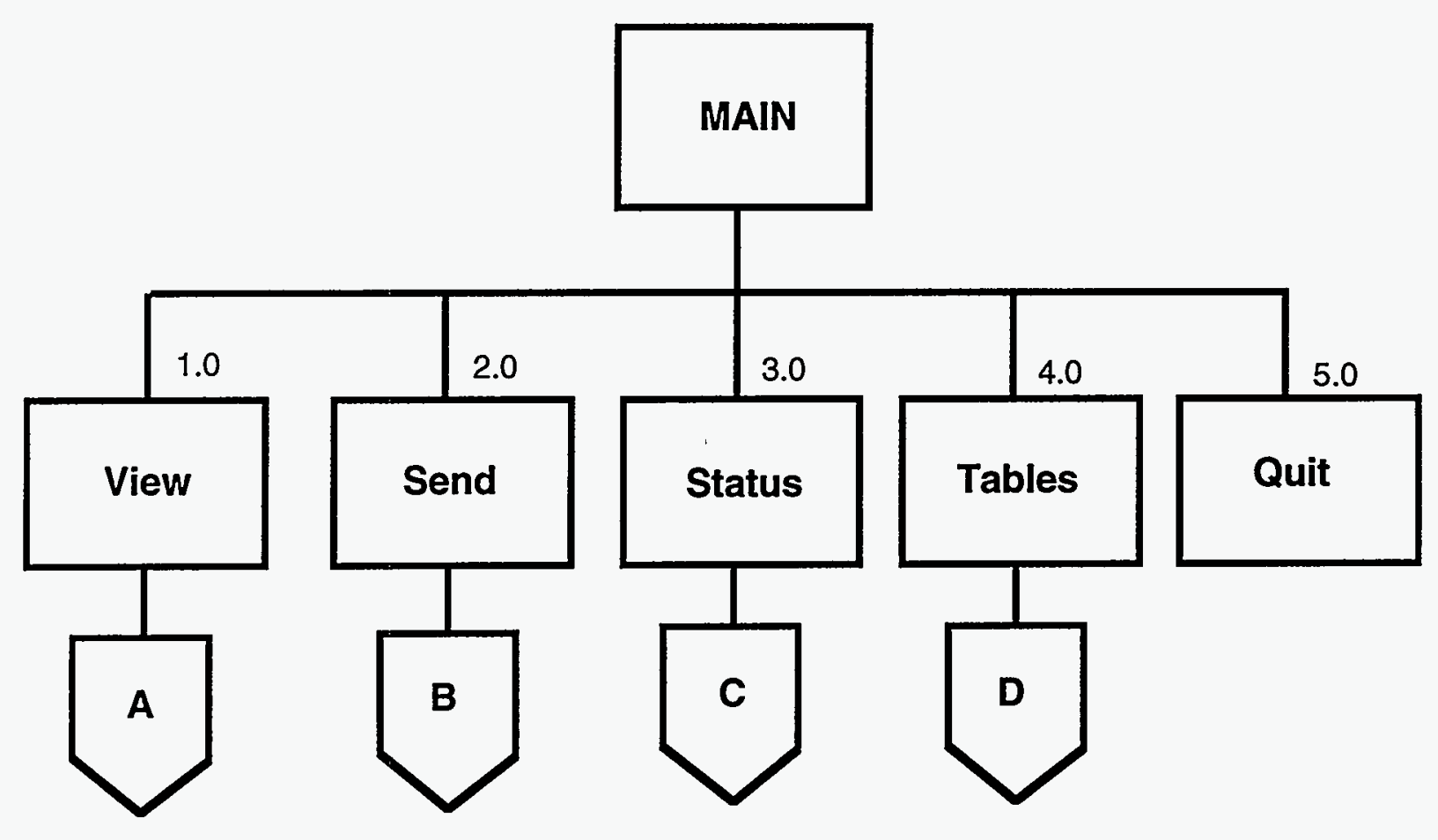

Fig. B-1. Flow chart for tag user interface program 

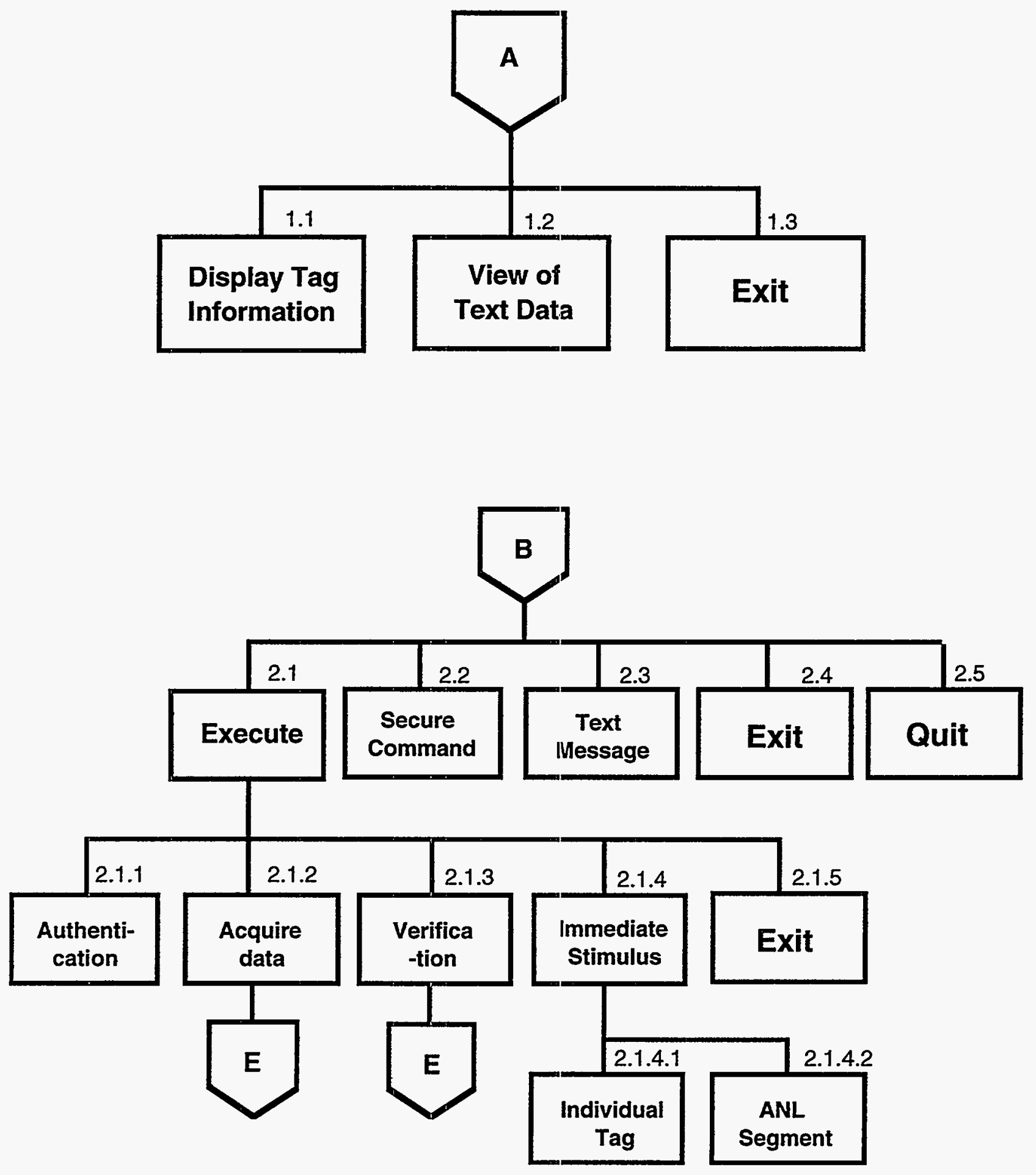

Fig. B-1. (Cont.) 

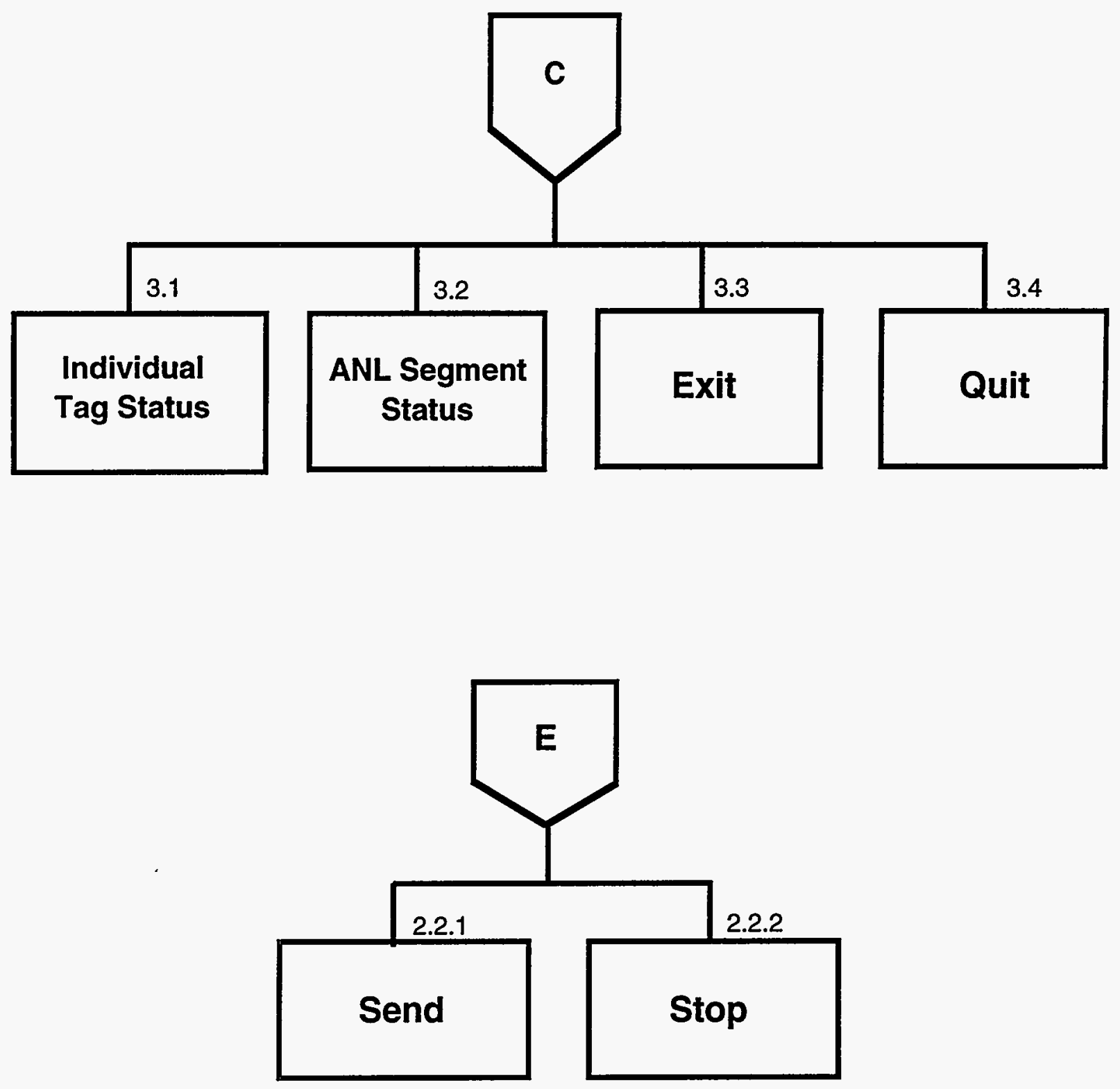

Fig. B-1. (Cont.) 


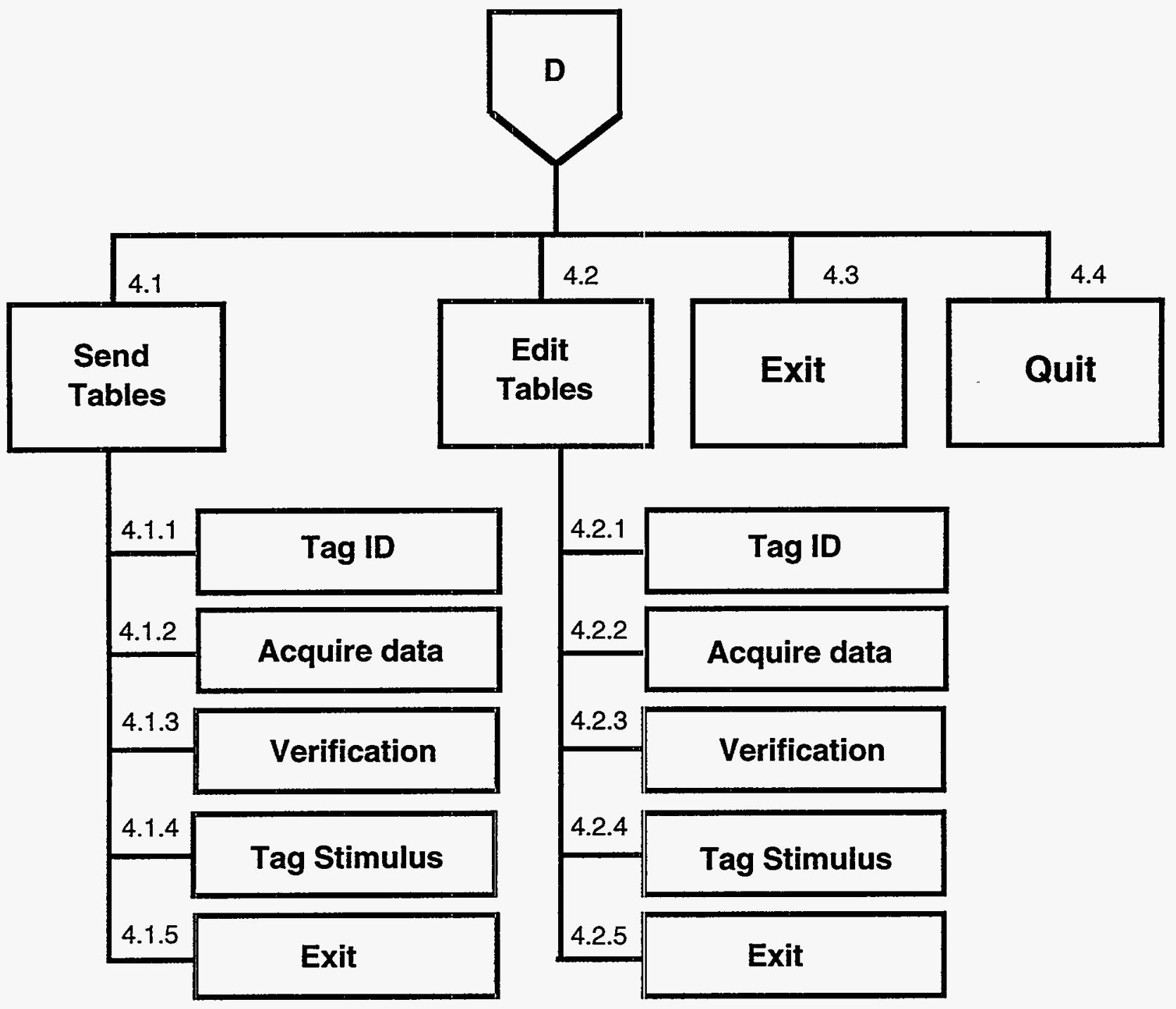

Fig. B-1. (Cont.) 
Appendix C: File List of Tag User Interface Program
anl_tag.c
anl_aux.c
dial_pc.c
log_on.c
log_off.c
get_msg.c
send_msg.c
display.c
execute.c
command.c
status.c
tables.c
anl_tag.exe
dial_pc.exe
log_on.exe
log_off.exe
get_msg.exe
send_msg.exe
feal8.h
pcio.asm
tagid.lis
comd.lis
tagid.tbl
ver_seq.tbl
auth_seq.tbl
acq_seq.tbl
anl_nmc.log
tag_stim.tbl
message.log
position.log
dial_log.log
tagkey.log
tagkey.ref 


\section{Distribution for ANL-95/16}

Internal

Y. Cai (10)

S. H. Sheen

R. D. Carlson (30)

R. A. Valentin (2)

H. Drucker

M. W. Wambsganss

E. R. Koehl (10)

R. W. Weeks

C. A. Malefyt

TIS Files

R. B. Poeppel

A. C. Raptis (5)

\section{External}

DOE-OSTI for distribution per UC-940 (92)

ANL Libraries

ANL-E (2)

ANL-W

Manager, Chicago Field Office, DOE

Director, Technology Management Div., DOE-CH

D. L. Bray, DOE-CH

A. L. Taboas, DOE-CH

Energy Technology Division Review Committee:

H. K. Birnbaum, University of Illinois, Urbana

R. C. Buchanan, University of Cincinnati, Cincinnati, OH

M. S. Dresselhaus, Massachusetts Institute of Technology, Cambridge, MA

B. G. Jones, University of Illinois, Urbana

C.-Y. Li, Cornell University, Ithaca, NY

S.-N. Liu, Fremont, CA

R. E. Smith, Altran Corp., Huntersville, NC

Michael O'Connel, DOE, Washington, DC

David Spears, DOE, Washington, DC

Glen Harrison, ORNL

Robert Rumble, LLNL 